\title{
Atypical parathyroid adenomas: challenging lesions in the differential diagnosis of endocrine tumors
}

\author{
Filomena Cetani ${ }^{1}$, Claudio Marcocci ${ }^{2}$, Liborio Torregrossa ${ }^{3}$ and Elena Pardi ${ }^{2}$ \\ 1 University Hospital of Pisa, Unit of Endocrinology, Pisa, Italy \\ 2Unit of Endocrinology, Department of Clinical and Experimental Medicine, University of Pisa, Pisa, Italy \\ 3University Hospital of Pisa, Division of Surgical Pathology, Pisa, Italy
}

Correspondence should be addressed to F Cetani: cetani@endoc.med.unipi.it

\begin{abstract}
Atypical parathyroid adenomas represent a group of intermediate form of parathyroid neoplasms of uncertain malignant potential which show some atypical histological features that represent a challenge for the differential diagnosis with parathyroid carcinomas. They may occur as sporadic or as a part of hereditary syndromes. The molecular signature of these neoplasms is still unknown and the germline CDC73 mutations appears to be the most common anomaly in this setting suggesting that these cases might represent variants of the hyperparathyroidism-jaw tumor syndrome. The identification of markers predicting the outcome is of great importance to guide an adequate postoperative monitoring and, the same time, relieve of the anxiety of relatively strict monitoring patients not at risk. This review will summarize the current knowledge of the clinical, biochemical, molecular and histological profile of atypical parathyroid adenomas.
\end{abstract}

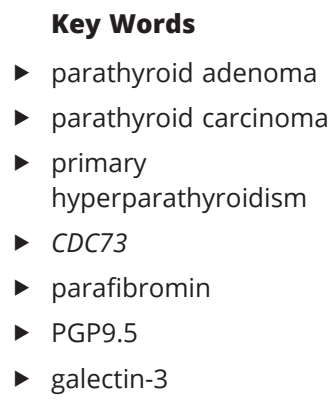

Endocrine-Related Cancer (2019) 26, R441-R464

\section{Introduction}

Parathyroid tumors are a heterogeneous group of tumors that affect $0.1-0.3 \%$ of the general population. They are mostly hyperfunctioning, that is produce an excessive and uncontrolled secretion of PTH determining primary hyperparathyroidism (PHPT), the third most common endocrine disease after diabetes and thyroid cancer (Bilezikian et al. 2018). Approximately $85 \%$ of the patients have a single parathyroid adenoma, 10\% hyperplasia and $3 \%$ double adenoma. Atypical parathyroid adenoma and carcinoma, in contrast, are rarer being the latter the rarest parathyroid tumor $(<1 \%)$ (Cetani et al. 2016, Saponaro et al. 2018). PHPT occurs as sporadic (90\%) or as familial (10\%) disease. Among the latter, multiple endocrine neoplasia (MEN) type 1 (MEN1), type 2A (MEN2A), type 4 (MEN4) and the hyperparathyroidism-jaw tumor syndrome (HPT-JT) are caused by known germline genetic mutations and are associated with a broad spectrum of endocrine and non-endocrine tumors (Cardoso et al. 2017). Most patients with HPT-JT are at increasing risk of parathyroid carcinoma (up to 37\%) and develop single or multiple cystic parathyroid adenomas and occasionally atypical adenomas (Marx \& Goltzman 2019). Because of the underlying genetic basis, these diseases may have different clinical features compared to the sporadic counterpart.

Atypical parathyroid adenomas represent a group of intermediate form of parathyroid neoplasms of uncertain malignant potential which show some atypical 
histological features (i.e. solid growth pattern, fibrous bands and cellular atypia), which represent a challenge for the differential diagnosis with parathyroid carcinomas. In this regard, it should be reminded that, at variance with parathyroid carcinoma, atypical parathyroid adenoma lacks evident signs of local invasion and/or metastasis. In some cases, the initial diagnosis of atypical adenoma needs to be revised to carcinoma because of the occurrence of local or distant metastasis during the follow-up (Sandelin et al. 1994). The reverse, even less frequently, may also occur when the initial diagnosis of parathyroid carcinoma is not confirmed by an expert endocrine pathologist (Ippolito et al. 2007, Cetani et al. 2008, Kumari et al. 2016, Ryhänen et al. 2017). Finally, there are cases in which the differential diagnosis between atypical parathyroid adenoma and carcinoma may be a major challenge also for an experienced pathologist. The macroscopic appearance at surgery is of limited help since in both cases the parathyroid lesions may appear firm and adherent to the adjacent structures, features that in the suspicion for malignancy may guide the surgeon to perform a more radical surgical approach.

The question of whether atypical parathyroid adenomas could represent an early stage of a parathyroid carcinoma, which is excised before the development of the molecular signature of malignancy responsible for invasive properties remains to be established. Immunohistochemical markers have been sought to help identifying atypical parathyroid adenoma carrying the risk of malignant behavior, but unfortunately, current data in small series of parathyroid typical and atypical adenoma and carcinoma have shown an overlap between the different tumors.

Our understanding of the molecular pathogenesis of parathyroid tumors has significantly increased over the last two decades, especially for parathyroid carcinoma. Conversely, no major progress has been made to define the molecular mechanisms underlying atypical parathyroid adenomas.

The clinical profile and outcome (recurrence rate and overall survival) of patients with atypical parathyroid adenoma seems to be less severe than that of patients with parathyroid carcinoma. In view of the diagnostic difficulties between these two conditions at histology the identification of markers capable of predicting the outcome of patients with atypical adenoma (low risk vs high risk) would be crucial in order to plan an adequate clinical management.
The aim of this review is to summarize the current knowledge of the clinical, biochemical, molecular and histological profile of atypical parathyroid adenomas.

\section{Medline search strategy}

We conducted a systematic search for the full articles through the public Medline database (https://www.ncbi. nlm.nih.gov/pubmed; last access: December 21, 2018) using as keywords either 'atypical parathyroid adenoma' or 'parathyroid atypical adenoma' or 'equivocal parathyroid adenoma' or 'parathyroid equivocal adenoma' and yielded 144, 181, 70 and 56 articles, respectively, after a filtration for the use of English language in the text. A further specific manual search was made checking our topic from the reference lists of relevant studies, thus allowing the finding of seven additional articles. Titles and abstracts of all identified articles were screened and full-text articles of studies that met the predefined eligibility criteria were obtained and carefully reviewed. We finally extracted data from a total of 92 different full articles after removal of duplicates and exclusion of articles where the presence of atypical features in parathyroid tumors were not based on histological examination of surgically removed tissue material. The reports described a total of 672 patients with a diagnosis of atypical parathyroid adenoma, mainly sporadic and including 24 members of FIHP, HPT-JT and MEN1 kindreds. Articles included 55 case series with comparative analyses and 36 case report studies dealing with 41 cases, 15 of which had a familial history of PHPT.

We reviewed all available information on demographic data, clinical presentation, pre-operative biochemistry, operative findings and procedures, histopathology and postoperative outcome from the case series and reports collected.

\section{Epidemiology}

Six hundred seventy-two patients have been reported according to the criteria of the research. All but 24 cases, which included members of FIHP, HPT-JT and MEN1 kindreds, were sporadic or otherwise not specified (Table 1). The pathological diagnosis of atypical parathyroid adenoma was made mostly according to the World Health Organization (WHO) criteria (see below) (DeLellis et al. 2004, 2017). The largest series has been reported by Schneider et al. (2015). 
Table 1 Demographic, biochemical, clinical, surgery-related features of patients with atypical parathyroid adenoma derived from the literature revision.

\begin{tabular}{|c|c|c|c|c|c|c|}
\hline & Total & cases $(n=672)^{a}$ & Sporadi & c cases $(n=331)^{b}$ & Familic & I cases $(n=24)^{c}$ \\
\hline & $n(\%)$ & Value & $n(\%)$ & Value & $n(\%)$ & Value \\
\hline Sex (total $n=466$; sporadic $n=281$; fami & $=23)$ & & & & & \\
\hline Male & $185(40)$ & & $116(41)$ & & $11(48)$ & \\
\hline Female & $281(60)$ & & $165(59)$ & & $12(52)$ & \\
\hline Age at diagnosis (years) (total $n=103, \mathrm{sp}$ & dic $n=44, f$ & amilial $n=24$ ) & & & & \\
\hline Mean \pm S.D. & & $43.3 \pm 18.9$ & & $48.1 \pm 18.5$ & & $25.6 \pm 8.1$ \\
\hline Median (range) & & $44(10-86)$ & & $50(16-80)$ & & $28(10-37)$ \\
\hline Clinical manifestations (total $n=242$, spc & $c n=107$, & amilial $n=13$ ) & & & & \\
\hline Renal involvement & $71(29)$ & & $25(21)$ & & $4(31)$ & \\
\hline Bone involvement & $44(18)$ & & $30(28)$ & & $2(15)$ & \\
\hline Both & $6(3)$ & & $3(3)$ & & $0(0)$ & \\
\hline $\begin{array}{l}\text { Palpable lesion (total } n=247 \text {, sporadic } \\
n=151 \text {, familial } n=3 \text { ) }\end{array}$ & $37(15)$ & & $15(10)$ & & $2(67)$ & \\
\hline Serum calcium level (mg/dL) (total $n=79$ & oradic $n=$ & 34 , familial $n=19$ ) & & & & \\
\hline Mean \pm S.D. & & $13.4 \pm 2.4$ & & $14.0 \pm 2.6$ & & $12.8 \pm 1.6$ \\
\hline Median (range) & & $12.9(10.2-23.2)$ & & $13.3(10.2-23.2)$ & & $12.1(11-16)$ \\
\hline Serum PTH level (ng/L) (total $n=74^{d}$, spo & $\mathrm{c} n=26, \mathrm{fa}$ & milial $n=20$ ) & & & & \\
\hline Mean \pm S.D. & & $782 \pm 712$ & & $951 \pm 871$ & & $637 \pm 697$ \\
\hline Median (range) & & $430(73-3242)$ & & $507(124-3242)$ & & $209(73-2164)$ \\
\hline $\begin{array}{l}\text { Adherence to adjacent structures (total } \\
n=230 \text {, sporadic } n=151 \text {, familial } n=4 \text { ) }\end{array}$ & $98(43)$ & & $78(52)$ & & $2(50)$ & \\
\hline Initial surgery (total $n=275$, sporadic $n=$ & familial $n$ & $=15)$ & & & & \\
\hline En bloc resection & $65(24)$ & & $41(21)$ & & $3(20)$ & \\
\hline Bilateral cervical exploration & $52(19)$ & & $46(24)$ & & $5(33)$ & \\
\hline Simple PTx & $155(56)$ & & $105(54.5)$ & & $7(47)$ & \\
\hline Sternotomy/thoracotomy & $3(1)$ & & $1(0.5)$ & & $0(0)$ & \\
\hline Tumor size $(\mathrm{cm})$ (total $n=55$, sporadic $n$ & familial $n$ & $=13)$ & & & & \\
\hline Mean \pm S.D. & & $2.7 \pm 1.4$ & & $3.2 \pm 1.6$ & & $2.3 \pm 1.1$ \\
\hline Median (range) & & $2.5(0.7-7.2)$ & & $3(1-7.2)$ & & $2.3(0.7-4)$ \\
\hline Tumor weight (g) (total $n=24$, sporadic $r$ & 3 , familial $r$ & $=1)$ & & & & \\
\hline Mean \pm S.D. & & $10.8 \pm 20.4$ & & $12.6 \pm 25.1$ & & 1.1 \\
\hline Median (range) & & $4.15(0.3-101)$ & & $3.8(0.3-101)$ & & 1.1 \\
\hline $\begin{array}{l}\text { Cystic featurese (total } n=125, \text { sporadic } \\
n=31 \text {, familial } n=11 \text { ) }\end{array}$ & $37(30)$ & & $7(22)$ & & $5(45)$ & \\
\hline Outcome (total $n=478$, sporadic $n=236$ & hilial $n=15$ & & & & & \\
\hline Cured & $457(96)$ & & $229(97)$ & & $9(60)$ & \\
\hline Persistence & $5(1)$ & & $2(1)$ & & $0(0)$ & \\
\hline Recurrence & $16(3)$ & & $5(2)$ & & $6(40)$ & \\
\hline Months to recurrence after first sur & (total $n=1$ & 0 , sporadic $n=3, \mathrm{f}$ & amilial $n=6$ ) & & & \\
\hline Mean \pm S.D. & & $94 \pm 69$ & & $76 \pm 82$ & & $126 \pm 58$ \\
\hline Median (range) & & $120(12-204)$ & & $48(12-168)$ & & $132(24-204)$ \\
\hline Follow-up (months) (total $n=57$, sporadi & 20, familic & $n=13)$ & & & & \\
\hline Mean \pm S.D. & & $62.6 \pm 61.4$ & & $38.6 \pm 39.2$ & & $104 \pm 91$ \\
\hline Median (range) & & $47(0.25-252)$ & & $21(0.25-120)$ & & $96(2-252)$ \\
\hline
\end{tabular}

The figures in parentheses indicate the number of patients with available information. Serum calcium, the most represented normal values were 8.5-10.5 and 8.8-10.4 mg/dL. Plasma PTH, the most represented normal values were 11-65, 15-60 and 15-65 ng/L.

alncludes one case with non-functioning atypical parathyroid adenoma. bIncludes one case with $C D C 73$ germline mutation and one case of clinical Multiple endocrine neoplasia type 1 with no family history. cFamilial cases include 17 Familial Isolated Hyperparathyroidism, 6 Hyperparathyroidism-jaw tumor and 1 multiple endocrine neoplasia type 1. dData from non-functioning atypical parathyroid adenoma were not included. eDetected at neck ultrasound and/or pathology.

In most consecutive series of patients undergoing surgery for PHPT, the incidence of atypical parathyroid adenoma ranged from 0.5 to $4.4 \%$ (de Meneses Montenegro et al. 2006, Ippolito et al. 2007, Juhlin et al. 2010, O'Neal et al. 2011, Ricci et al. 2012, Chandramohan et al. 2014,
Haglund et al. 2015, McCoy et al. 2015, Quinn et al. 2015, Schneider et al. 2015, Ozolins et al. 2016, Mamedova et al. 2017). An incidence as high as $14 \%$ has been reported in the Asian countries (Cakir et al. 2016, Kumari et al. 2016, Hu et al. 2018). (c) 2019 Society for Endocrinology Published by Bioscientifica Ltd. Printed in Great Britain 
At variance with benign disease, in whom the women predominate over men with a ratio of 3-4:1, but similar to parathyroid carcinoma in which the ratio between gender is comparable, atypical parathyroid adenomas occur with a ratio of 1.5:1. The median age at diagnosis is 44 years, which is, as in PC, a decade earlier than the typical age of benign disease. As expected, the familial cases were younger compared to their sporadic counterpart (median age 28 (10-37) vs 50 (16-80) years) (Table 1$)$.

\section{Pathogenesis}

\section{Genetic alterations}

The pathogenic mechanisms underlying the origin of atypical adenomas are currently unknown and a few studies on a small sample size have been carried out so far.

Our effort should be directed to understand whether atypical adenomas might represent a pre-malignant lesion or might not have a true malignant potential, thus sharing genetic features with parathyroid carcinoma or benign parathyroid adenoma, respectively.

Clonality in tumor origin has important implications for cancer risk assessment and treatment. A step-wise accumulation of mutations within the lineage of a single cell supports a malignant progression model for which aggressive tumors bear at equal or even greater frequency the same genetic alterations early observed in benign neoplasia and gain more malignant potential throughout the lifetime (Vogelstein et al. 2013). Multiclonal tumor origin is the predominant mode of tumorigenesis of some cancer types, like colorectal cancer, whereas other tumors, such as many of the myeloid cell lineages, seem to rather have a monoclonal tumor origin. If parathyroid tumorigenesis would follow the multiclonal origin model we would expect that known molecular events characterizing parathyroid adenomas, that is $11 \mathrm{q}$ loss and/or MEN1 mutations, would also be present in carcinomas at a frequency $\geq 35 \%$ (Pardi et al. 2013, Brewer et al. 2019). The finding that such alterations occur at a very low frequency in parathyroid carcinoma suggests that most parathyroid cancers arise de novo, rather than evolve from a preexisting benign adenoma (Costa-Guda et al. 2013, Brewer et al. 2019).

Somatic loss-of-function mutations of the CDC73 tumor suppressor gene, encoding parafibromin, are the most common genetic abnormality found in sporadic parathyroid carcinomas (up to 70\%) (Cetani et al. 2018). Conversely, CDC73 mutations are very rarely detected in benign adenomas (Howell et al. 2003, Cetani et al. 2004a, Krebs et al. 2005, Bradley et al. 2006, Guarnieri et al. 2012). Of note, germline mutations of the CDC73 gene are present in about $90 \%$ of patients with HPT-JT and in one-third of patients with apparently sporadic parathyroid carcinoma even in the absence of family history, suggesting a high risk for the patients and relatives to develop HPT-JT-related tumors. This inherited syndrome is characterized by the asynchronous development of parathyroid tumors, a variety of kidney lesions, benign ossifying fibroma of mandible/maxilla and uterine tumors (Cardoso et al. 2017). As mentioned before, the prevalence of parathyroid carcinoma in these patients is much higher than in sporadic cases (up to 37 vs $1 \%$, respectively). In this setting, rare patients have a parathyroid carcinoma that has been progressed from a benign or atypical parathyroid adenoma (Brewer et al. 2019). However, as underlined in the pathology section, since the histological diagnosis of atypical adenomas and carcinomas could be very challenging, as to whether in HPT-JT, there is a true progression from benign to malignant phenotype remains unclear.

On the basis of the evidence that $C D C 73$ has an important role in parathyroid carcinoma, alterations of this gene have also been searched for in atypical parathyroid adenomas.

Inactivating $C D C 73$ mutations, including two large deletions spanning exons 1-10 of the gene were identified in 24 of $63(38 \%)$ cases and in all but one (1.5\%) case were at germline level (Table 2). Seventy-three percent of germline mutations were found in familial cases (11 patients with FIHP and 4 with HPT-JT) and 7 in apparently sporadic PHPT (Table 2). Somatic CDC73 mutation screening was only performed in seven studies which included 27 neoplasms (Bradley et al. 2006, Juhlin et al. 2006, Mizusawa et al. 2006, Cetani et al. 2007, Guarnieri et al. 2012, Sulaiman et al. 2012a,b). Only four somatic CDC73 mutations were detected. However, three mutations represented the somatic hit associated with germline mutations (in two members of FIHP families and in a 58-year-old man with apparently sporadic PHPT) (Bradley et al. 2005, Kelly et al. 2006, Guarnieri et al. 2012). The latter patient and one FIHP relative remained normocalcemic up to the latest evaluation 27 and 24 months after surgery, respectively, whereas no information on the outcome was reported for the remaining patient. Interestingly, Sulaiman et al. described a PHPT patient carrying a germline CDC73 mutation who developed a benign and an atypical adenoma (Sulaiman et al. 2012a). A somatic hit, different from the germline CDC73 mutation, 


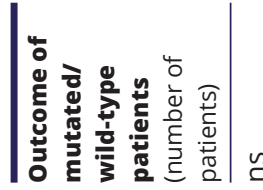

$\mid$ ऐ $\mid$

동 $\stackrel{\sim}{\sim}$

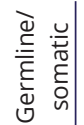

مإِ

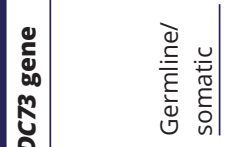

¿ั

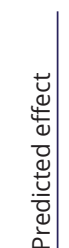

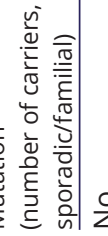

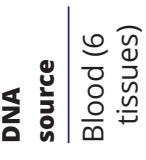

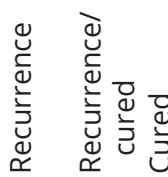

气

气

우

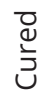

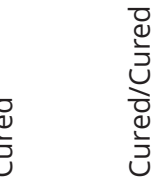

总

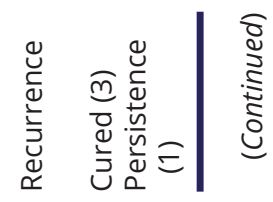

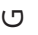

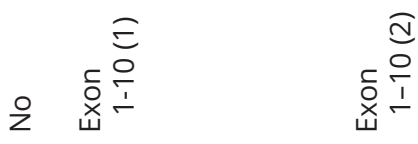

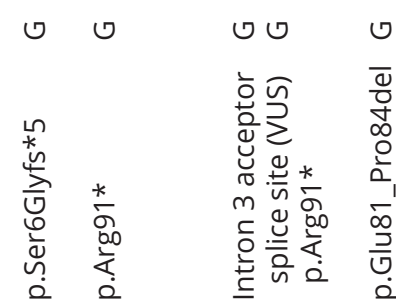

io

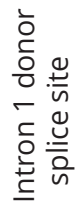
은

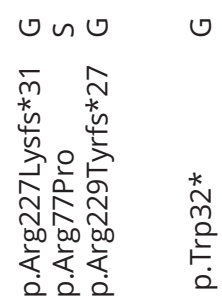

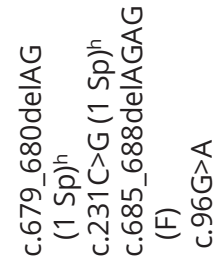

$\frac{\frac{0}{0}}{\frac{\frac{\pi}{5}}{\frac{m}{m}}}$

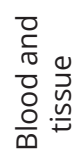

은

$\frac{0}{0}$
$\frac{0}{\pi}$
$\frac{0}{0}$
$\frac{0}{n}$
$\frac{0}{n}$
믐

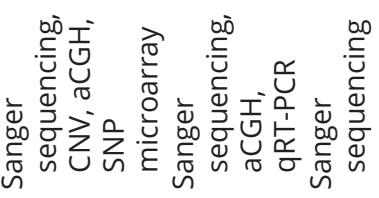

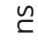

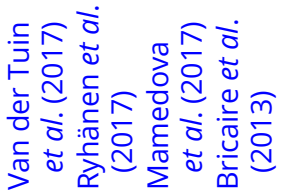

요돈

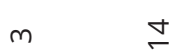

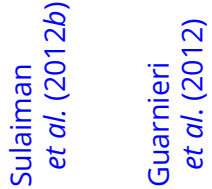

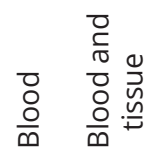

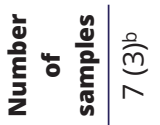

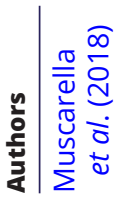

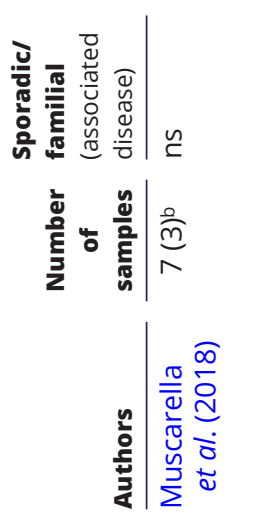

https://erc.bioscientifica.com https://doi.org/10.1530/ERC-19-0135 


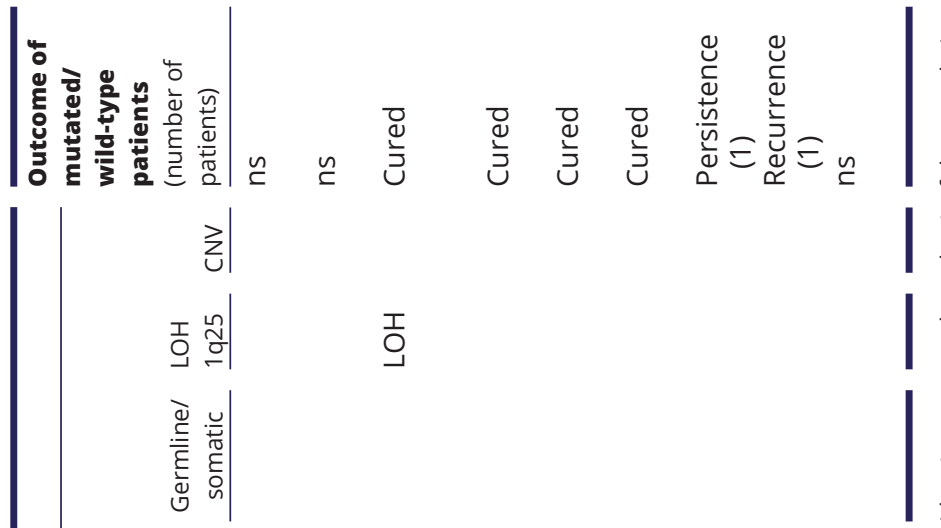

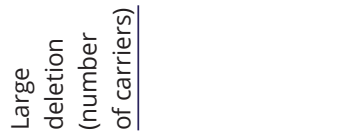

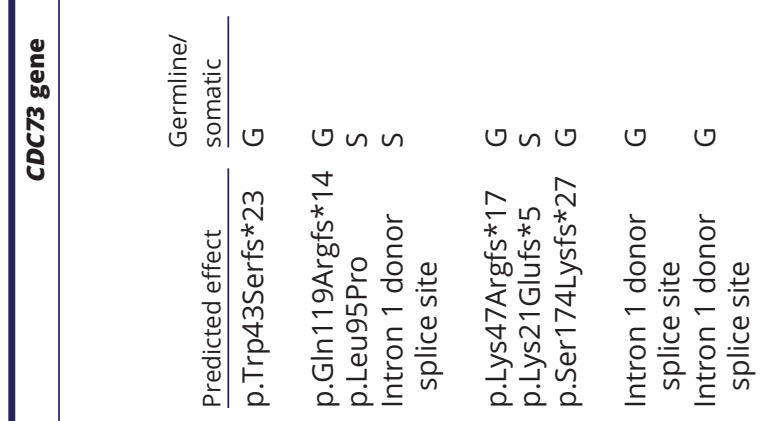

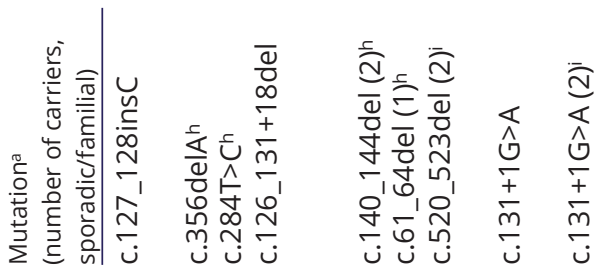

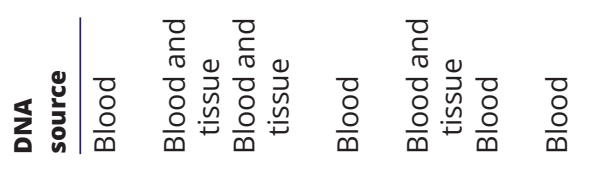

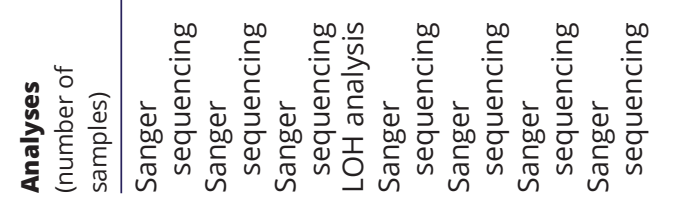

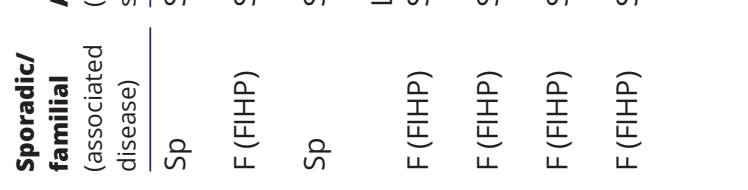

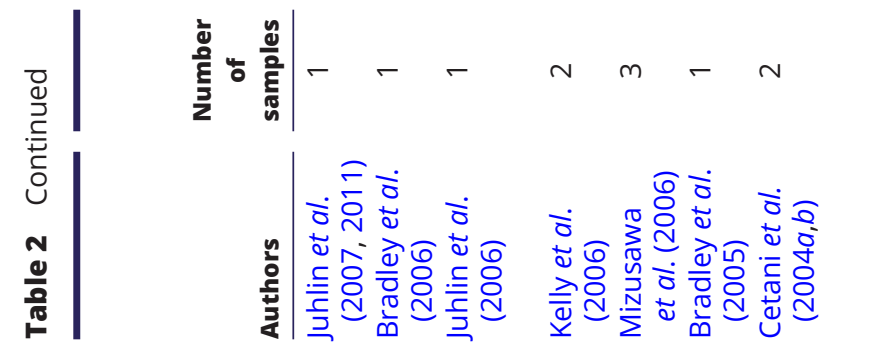


was found in the benign but not in the atypical adenoma, which was diploid at the CDC73 locus. Nonetheless, the benign adenoma harbored less cytogenetic anomalies, compared to the atypical adenoma and parathyroid carcinomas evaluated in the same study. Further studies in the atypical adenoma, using the genome-wide highresolution array-CGH technique, revealed a wide DNA copy number alterations at several chromosomal loci (extensive gains on 1p, 16, 17, 19, 20 and 22, small gains on chromosome 11 and 12, including MEN1 and CDK4 loci, respectively). Interestingly, a similar profile was found in three carcinomas included in the study. Finally, the atypical adenoma also displayed loss at 9p23-24.1 loci that was also identified in a sporadic parathyroid adenoma. Despite the interesting molecular signature of this atypical adenoma, being based on a single tumor, the authors suggested doing further studies using a larger sample size to confirm the data.

In summary, exclusive $C D C 73$ somatic mutations are very rare in atypical parathyroid adenomas, suggesting a minor pathogenic role, if any, in these neoplasms. Nevertheless, an interesting study generating parathyroidspecific $C d c 73$-knockout mice, resulted in mice deleted for one or both $C d c 73$ alleles that developed parathyroid tumors having in $75 \%$ of the cases nuclear pleomorphism, fibrous septa and galectin-3 overexpression, consistent with the histological diagnosis of atypical parathyroid adenomas. Parathyroid tumors of $\mathrm{Cdc73} 3^{+/-}$and conditional parathyroid-specific mice $\left(C d c 73^{+/ L / P T H-C r e}\right.$ and $C d c 73^{\mathrm{L} / \mathrm{L} / \mathrm{PTH}-\mathrm{Cre})}$ had significantly increased proliferation rate, higher mean serum calcium and PTH levels than wild-type littermates. Thirty-three percent of female $C d c 73^{+-}$mice developed uterine neoplasms, resembling HPT-JT syndrome in human (Walls et al. 2017).

The oncosuppressor MEN1 gene and CCND1 oncogene have been clearly established as drivers of benign parathyroid tumorigenesis (Brewer et al. 2019). A small subset of patients with parathyroid carcinoma carries MEN1 mutations and their frequency is much lower than that reported in sporadic parathyroid adenoma (6 vs $35 \%$, respectively) (Brewer et al. 2019). Loss-of-function MEN1 mutations have been searched for in ten atypical parathyroid adenomas and only one germline mutation (c.253A $>$ T, p.127S) in exon 2 was detected in a MEN1 patient (Cetani et al. 2002, Juhlin et al. 2006, Mizusawa et al. 2006, Sulaiman et al. 2012a, Pal et al. 2018).

Other genes have been evaluated as possible contributors for the pathogenesis of atypical parathyroid adenomas. Loss-of-function mutations of the calciumsensing receptor (CASR), which are responsible for familial hypocalciuric hypercalcemia type 1 and neonatal severe hyperparathyroidism and FIHP, were not detected at germline level in three relatives of FIHP and HPT-JT families bearing atypical adenomas (Mizusawa et al. 2006). Such mutations have also not been detected in sporadic parathyroid adenomas (Hosokawa et al. 1995, Cetani et al. 1999). Only one case of apparently sporadic parathyroid adenoma was found to harbor a CASR mutation in the germline (Guarnieri et al. 2010).

Genetic testing of $\beta$-catenin (six cases), enhancer of zeste homolog 2 (EZH2) and zinc finger X-linked ( $Z F X)$ (12 cases) genes was negative. Remarkably, such mutations also appear to be very rare in parathyroid adenomas (Cromer et al. 2012, Sanpaolo et al. 2016, Romano et al. 2017).

Allelic loss (LOH) at different chromosomal loci including 12 tumor suppressor genes (CDKN1A, CDKN2A, TP53, CDC73, VHL, APC, PTEN, NM23, KAI1, MEN1, RB1, and NF2) was identified in 25 of 38 (66\%) sporadic atypical parathyroid adenomas (nine cases at CDKN1A, four at RB1 and six at CDC73 and PTEN) (McCoy et al. 2015). Similarly, this molecular profile was partially shared by parathyroid carcinomas. Of interest, LOH of NM23, VHL and APC was only observed in parathyroid carcinomas but not in atypical adenomas. Notably, the same authors in a previous study found a different $\mathrm{LOH}$ profile between benign adenoma and parathyroid carcinoma, particularly at CDC73 and RB1 locus, which were more frequently associated with malignant disease (Yip et al. 2008).

\section{Epigenetic alterations}

The role of epigenetic alterations in atypical parathyroid adenomas has been investigated in even fewer studies.

Global hypomethylated genome together with hypermethylation of specific genes has been described in many human malignant tumors. A global hypermethylation, compared with normal parathyroid glands, has been reported in parathyroid carcinomas though all of the hypermethylated genes in parathyroid carcinomas were also hypermethylated, at lesser extent, in benign parathyroid tumors (Starker et al. 2011, Barazeghi et al. 2016, Verdelli \& Corbetta 2017). Sulaiman and coworkers investigated the methylation state of genes commonly involved in the pathogenesis of human cancer and particularly of parathyroid tumors (i.e. CDKN2A, PAX1, RASSF1A, CTNNB1, SFRP1, APC, CDC73, MEN1, CASR and VDR). They found a concordant hypermethylation of promoter $1 \mathrm{~A}$ of $A P C, C T N N B 1$ and RASSF1A in three atypical adenomas as well as 
in three parathyroid carcinomas and 66 parathyroid adenomas. Conversely, they did not find hypermethylation of MEN1 or CDC73 promoter among the three categories of tumors, regardless of their mutational state. Finally, hypermethylation of SFRP1 gene, likely involved in the activation of the Wnt/ $\beta$-catenin signaling pathway, was found in parathyroid carcinomas but not in atypical adenomas and benign adenomas, suggesting a putative role of this protein as a marker for parathyroid malignancy (Sulaiman et al. 2013).

Several studies have outlined an important role of miRNAs for the prediction of prognosis and outcome in many human cancers (Kwok et al. 2017). miRNAs are small endogenous non-coding RNA molecules (18-25 nucleotides) which may repress protein expression. The only study addressing the role of miRNAs in atypical parathyroid adenoma was published in 2018, investigating the epigenetic signature of miRNAs in 19 atypical parathyroid adenomas compared with parathyroid carcinomas and adenomas (Verdelli et al. 2018). An overexpression of miR-372 was found in 14 of 19 (74\%) cases. The level of overexpression was similar to that observed in parathyroid cancers and significantly higher than in benign parathyroid adenomas. A significant reduction of mRNA levels of its target genes, namely CDKN1A (P21), large tumor suppressor kinase 2 (LATS-2) and CCDN1 (cyclin D1), as well as an inhibitory effect at protein level was also identified (Verdelli et al. 2018).

Although epigenetic investigation is limited and additional studies are necessary, these data suggest a potential role of epigenetic alterations in the pathogenesis of atypical parathyroid adenomas.

\section{Pathological features}

The overlapping of histopathologic features between carcinomas and atypical adenomas can sometimes make the diagnosis of atypical adenoma very challenging (Delellis 2011). According to the histopathological criteria proposed by the WHO, the diagnosis of malignancy in parathyroid gland should be limited to tumors with clear and unequivocal signs of invasive growth, such as neoplastic infiltration of adjacent tissues (as the soft tissues or the thyroid gland), vascular invasion, perineural space invasion and/or documented metastases (WHO 4th edition) (DeLellis et al. 2017). The WHO and Armed Forces Institute of Pathology (AFIP) defined an unequivocal vascular invasion when the neoplastic cells are located inside capsular or pericapsular vessels, attached to the vessel wall, generally associated with fibrin thrombi, in presence or not of endothelial covering (Rosai et al. 2014). Capsular invasion is evident when a tongue or mushroom-like protrusion of the neoplasm goes over the fibrous capsule and variably extends into adjacent soft tissue. Other histological features of parathyroid carcinoma, variably represented, include the presence of foci of coagulative necrosis, variable degree of pleomorphism, including the presence of macronucleoli in some cases, and the presence of broadbands of fibrous connective tissue. However, none of the latter features is specific of malignancy, since variably observed both in benign and malignant tumors of the parathyroid gland (Rosai et al. 2014). The term 'atypical adenoma' is referred to a group of lesions of the parathyroid gland showing some histological features exhibited by carcinomas, in the absence of unequivocal evidence of invasive growth (Rosai et al. 2014, DeLellis et al. 2017). This subset of parathyroid lesions has also been labeled as tumors of uncertain malignant potential. Both macroscopically and microscopically, atypical adenoma can simulate a carcinoma, exhibiting the following features: (i) adherence to contiguous structures, in absence of clear invasion; (ii) banding fibrosis with or without hemosiderin deposition; (iii) entrapment of neoplastic cells within the fibrous capsule; (iv) solid/trabecular growth patterns and (v) mitotic activity (Rosai et al. 2014) (Fig. 1). The banding fibrosis appears as collagenous bands originating from the fibrous capsule and subdividing the tumor in variablesized nodules. In some cases, the fibrous bands may create the entrapment of neoplastic cells in the context of the capsule, simulating capsular invasion (known as pseudocapsular) (DeLellis 2008). Moreover, fibrous bands in association to cystic degeneration may create adherence of the tumor to the surrounding structures, giving the macroscopic impression of malignancy at the time of surgery (Fernandez-Ranvier et al. 2007). Most carcinomas have a prevalent solid growth pattern associated to a variable quote of trabecular organization. More rarely, carcinomas can exhibit a follicular pattern, a spindle cell pattern or rarely a carcinosarcomatous pattern (Rosai et al. 2014). The growth pattern, as well as the cellular composition (chief cells, oncocytic cells or clear cells) is not specific of malignancy. Since many carcinomas exhibit bland cytological features, the presence of cellular atypia and pleomorphism are not useful for the diagnosis of carcinoma (Schantz \& Castleman 1973). As in other endocrine tumors, the presence of enlarged hyperchomatic or even bizarre nuclei is not specific of malignancy, since variably observed in (c) 2019 Society for Endocrinology Published by Bioscientifica Ltd. Printed in Great Britain 


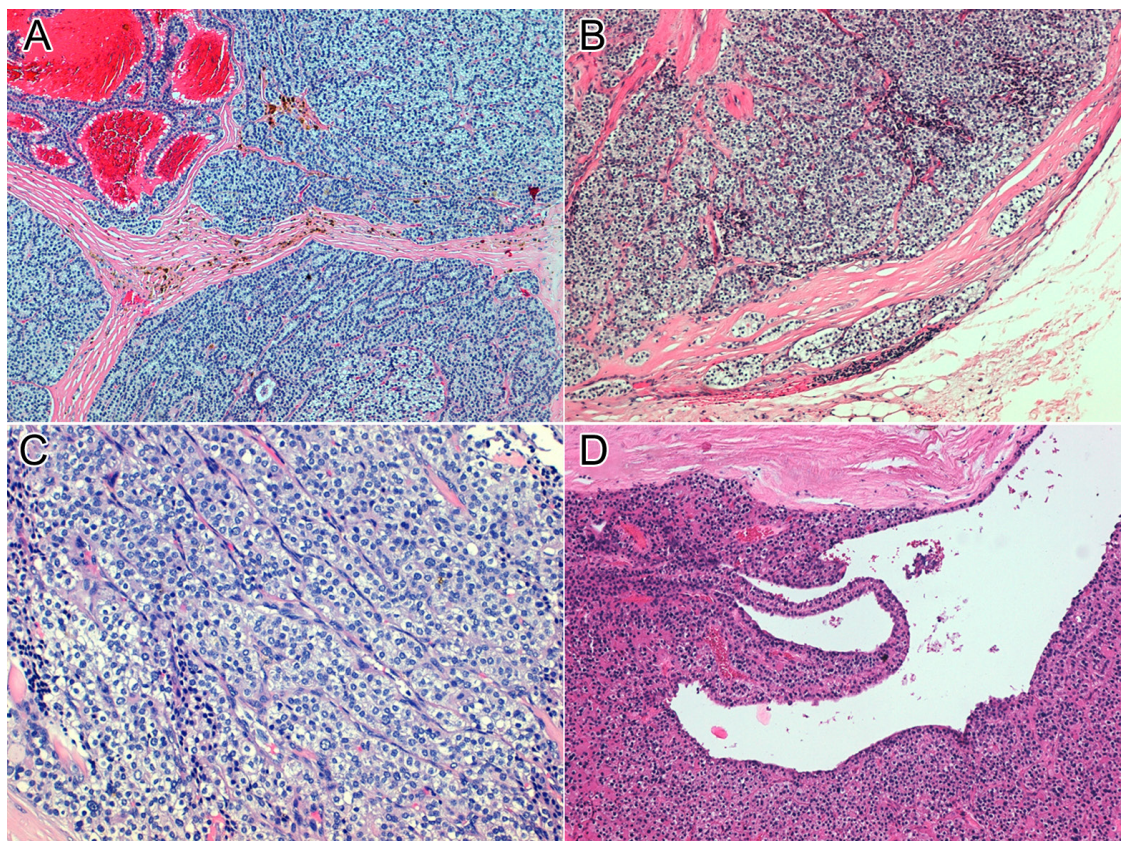

\section{Figure 1}

Representative histopathological images of atypical parathyroid adenoma. (A) This atypical parathyroid adenoma has irregular nodules composed of monotonous chief cells separated by prominent fibrous bands with hemosiderin deposition and marginal cystic degeneration (hematoxylin and eosin (H\&E) staining, original magnification $\times 200$ ). (B) An entrapment of the tumor cells within the fibrous capsule of the neoplasm is shown (H\&E staining, original magnification $\times 100$ ). (C) This tumor is composed mostly of chief cells with a minority of clear cells. The neoplastic cells show mild nuclear pleomorphism and trabecular growth pattern (H\&E staining, original magnification $\times 200$ ). (D) This tumor shows a prominent cystic degeneration (H\&E staining, original magnification $\times 100$ ). parathyroid adenomas (Rosai et al. 2014, DeLellis et al. 2017). Nonetheless, some of the atypical features may occasionally be also found in benign adenomas. Of note, Sulaiman and coworkers found the presence, although at limited extent, of almost one of such characteristics (i.e. trabecular growth pattern, cellular pleomorphism or fibrous bands) in an up to 33\% of benign adenomas (Sulaiman et al. 2012b). A mitotic activity in excess of 5 mitoses per 50 high power microscopic fields, in combination with the presence of foci of coagulative necrosis and macronucleoli, has been proposed as a triad to label parathyroid lesions with a high risk of malignant behavior, in terms of disease recurrence (Bondenson et al. 1993). The presence of atypical mitosis and focal areas of necrosis, though considered as criteria of malignancy, has also been described in a minority of atypical parathyroid adenomas (Katz et al. 2012, Ricci et al. 2012, Nair et al. 2013, Ramaswamy et al. 2017, Ryhänen et al. 2017, Pal et al. 2018, Silva-Figueroa et al. 2018).

Most of the studies included in this review have based the diagnosis of atypical adenoma on WHO criteria. However, there is no general consensus about the number of single histological atypical features to consider in order to classify a parathyroid neoplasm as atypical, rather than malignant or benign. As a matter of fact, the histological diagnosis of atypical parathyroid adenoma is strictly related to the lack of evidence of unequivocal findings of malignancy. Having said that, the correct diagnosis mainly depends on the meticulous examination of serial histological sections and their interpretation is at risk of subjective bias. Indeed, even between experienced endocrine pathologists exists some degree of inter-observer variability, with obvious impact on over- or under-diagnosis of specific types of parathyroid neoplasms, making difficult the comparison of data between different institutions.

Some authors, according to the criteria of Seethala and coworkers (Seethala et al. 2009), defined the diagnosis of atypical adenomas when at least two of the following features were present, namely intraoperative adherence, bands of fibrosis, pronounced trabecular growth, strong mitotic activity, necrosis, diffuse sheet-like monotonous small cells with high nuclear/cytoplasmic ratio, cellular atypia and nucleolomegaly, in the absence of unequivocal signs of malignancy (Mishra \& Newman 2014, McCoy et al. 2015, Cakir et al. 2016, Ozolins et al. 2016). Conversely, Kumari and coworkers, according to the histological criteria of Chan, established the diagnosis of atypical adenoma when one to three of the above features were present (Chan 2007, Kumari et al. 2016).

When histological data from different studies included in this review were pooled together, thick fibrous bands and trabecular growth pattern were the most representative morphological characteristics of atypical parathyroid adenomas (76 and 67\%, respectively), followed by the presence of mitotic figures/high mitotic activity (52\%), pseudocapsular invasion (42\%), cellular pleomorphism (30\%) and nuclear atypia (24\%) (Fig. 2). Increased mitotic activity best characterized carcinomas compared to atypical adenomas and benign adenomas 


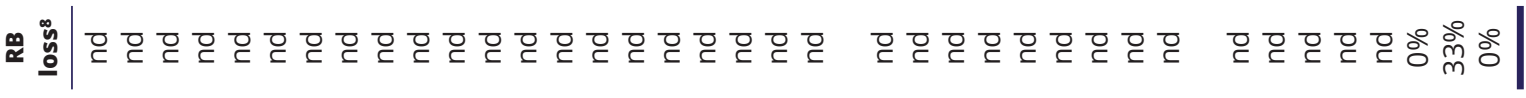

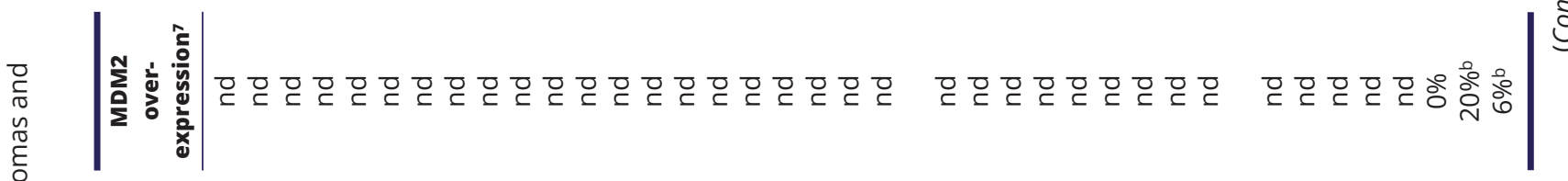

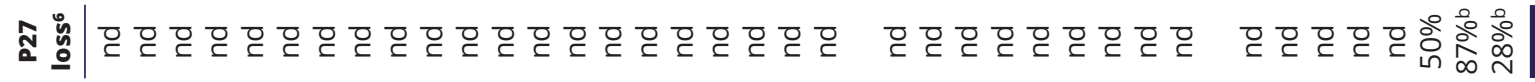

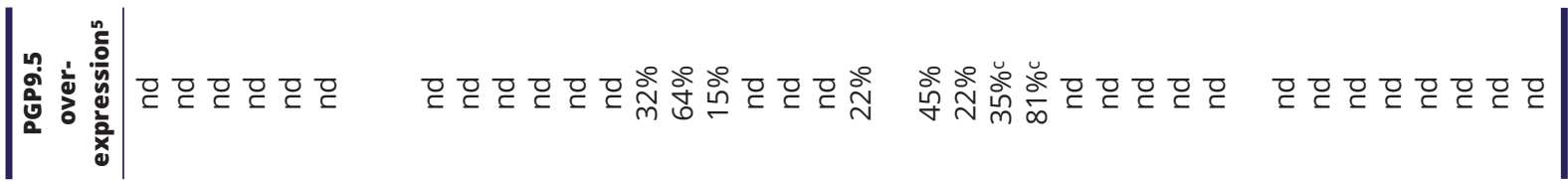

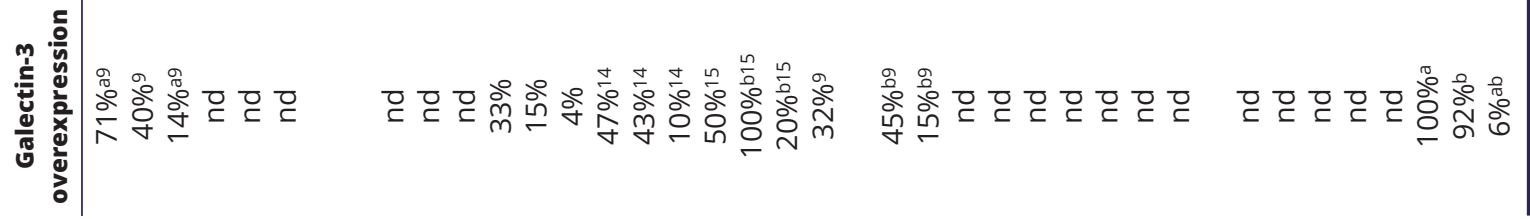

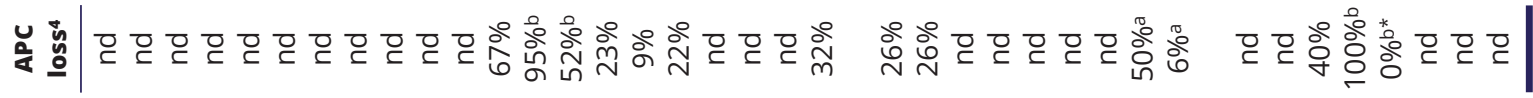

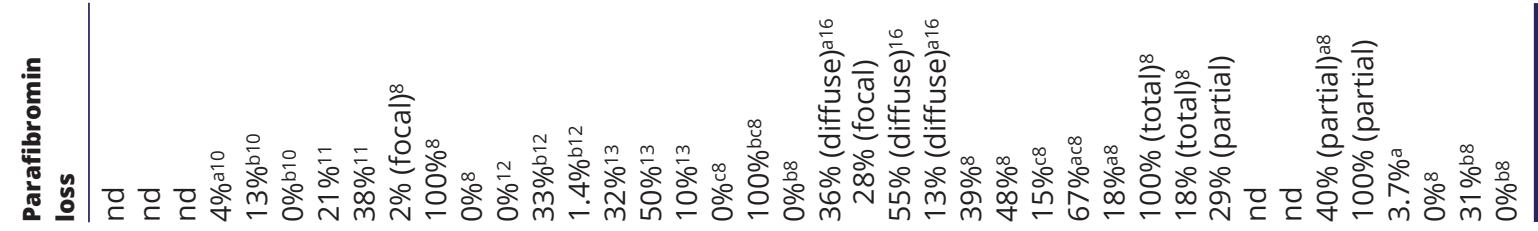

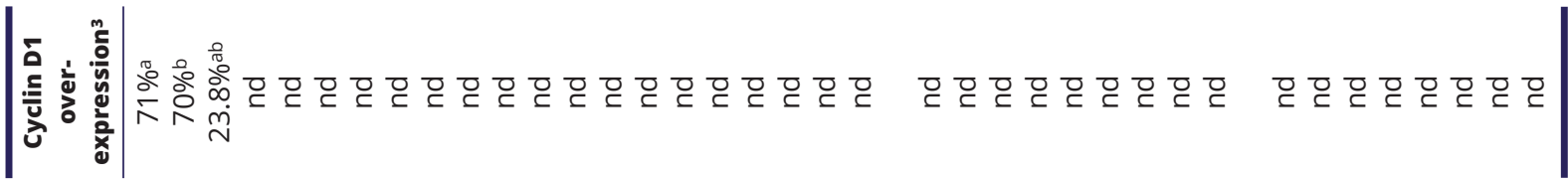

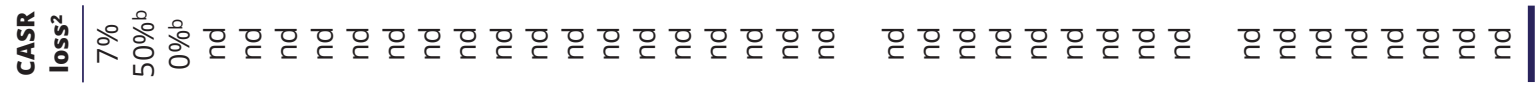

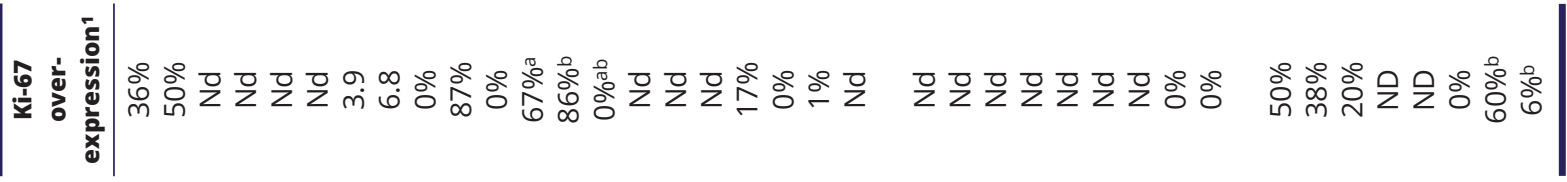

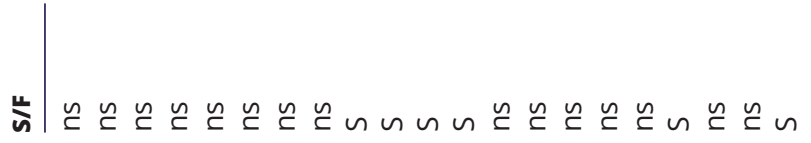

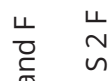

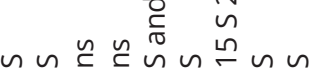

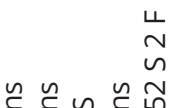

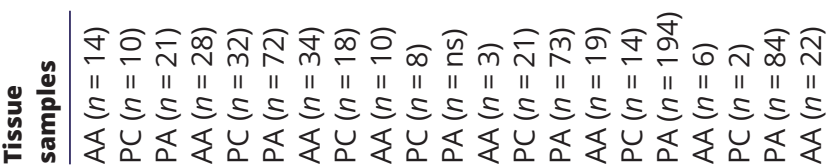

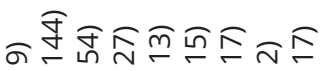
"1 111111111111

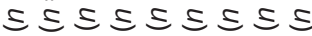

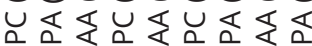
तิ "I II II II II II

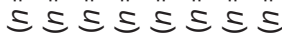

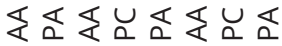




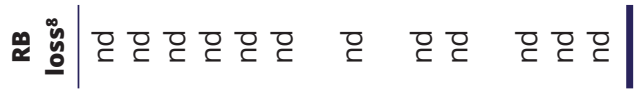

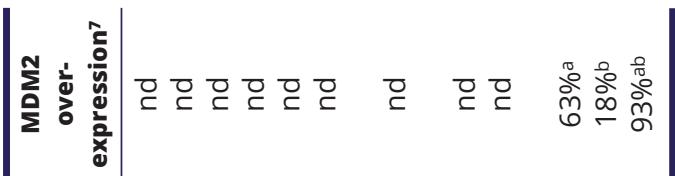

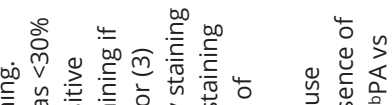

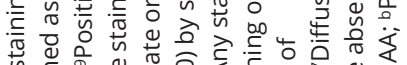

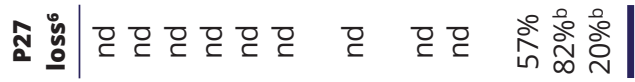

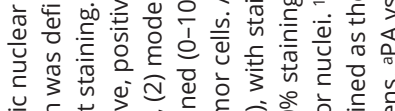

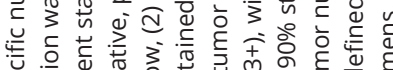

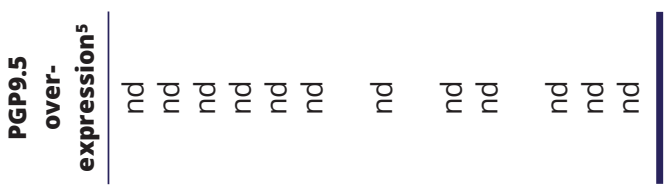

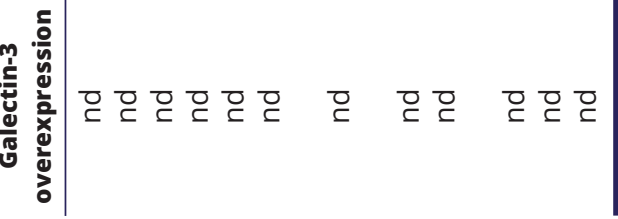

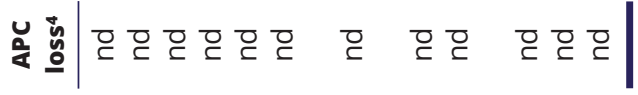

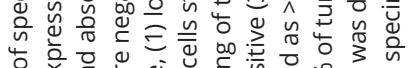

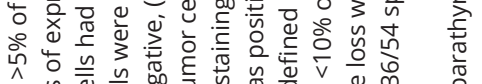

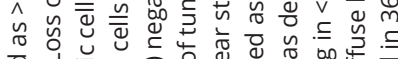

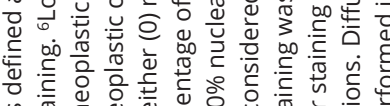

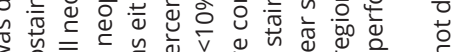

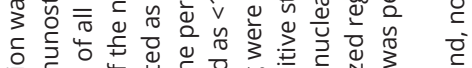

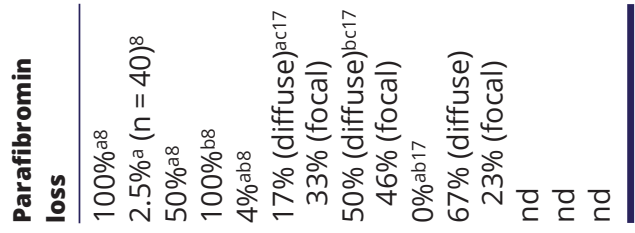

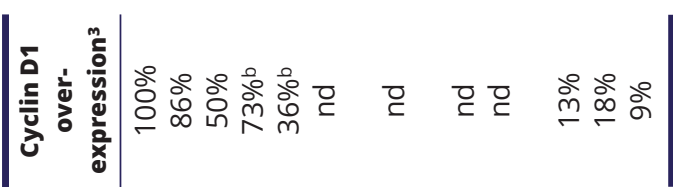

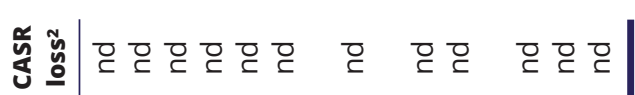

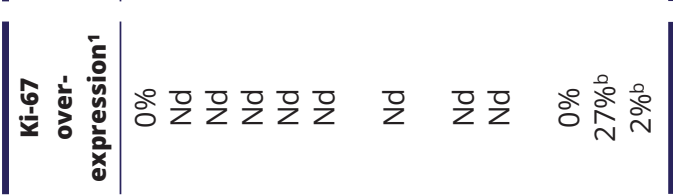

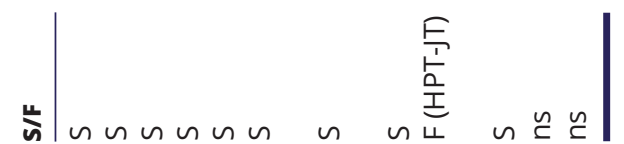

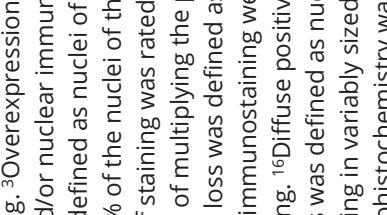

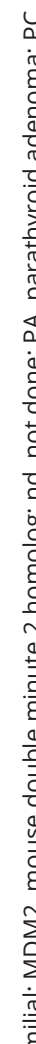

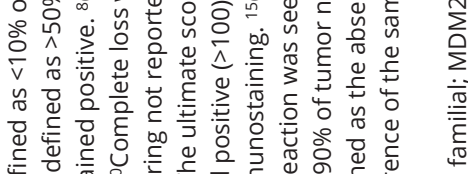

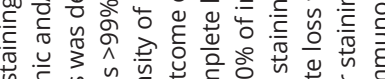

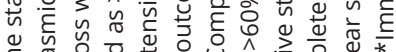

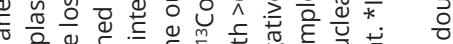

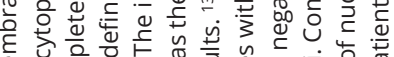

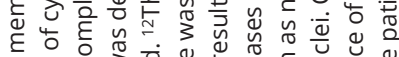

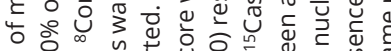

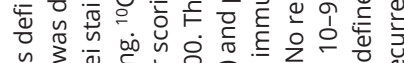

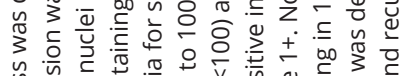

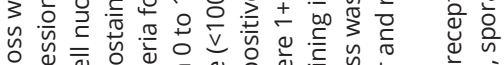

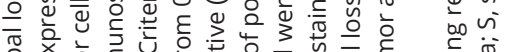

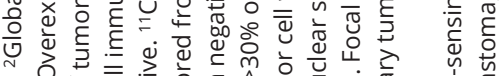

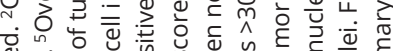

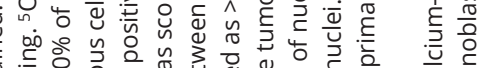

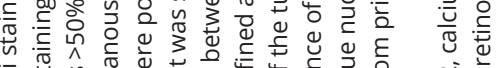

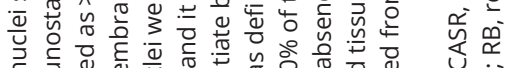

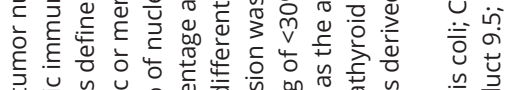

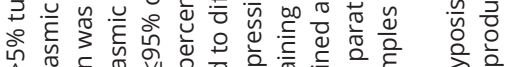
ᄉ्र

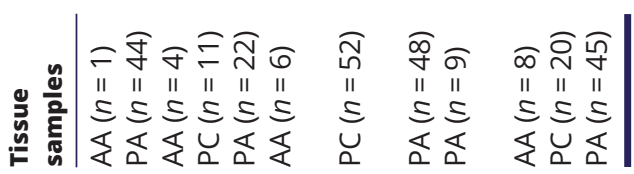




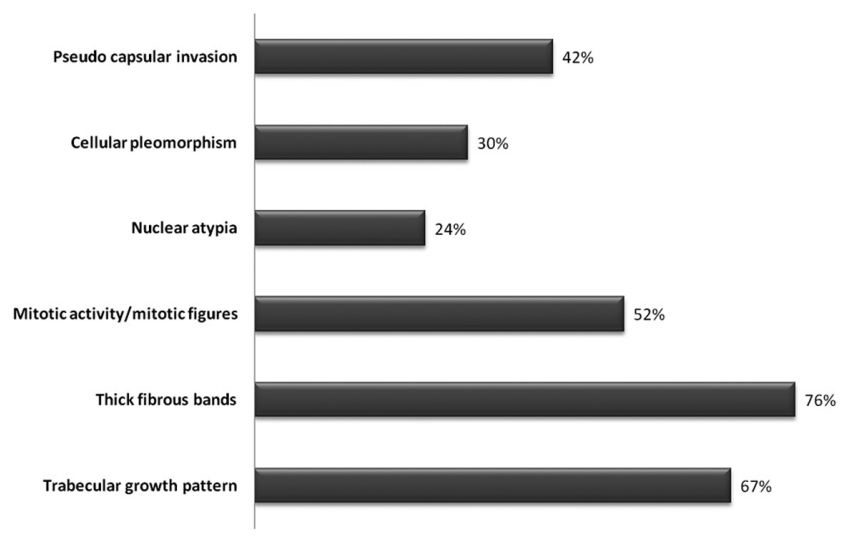

Figure 2

Main histological features reported in atypical parathyroid adenomas.

(up to 81 vs 38 and 7\%, respectively), whereas fibrous bands were similarly present in carcinomas and atypical adenomas compared to benign adenomas (up to 100 vs 83 and 9\%, respectively) (Table 4).

\section{Immunohistochemical markers}

In the last decades, a great effort has been made to evaluate the role of immunohistochemical markers as an aid to routine histology in the differential diagnosis of parathyroid tumors especially to evaluate the risk of malignancy in tumors with atypical features.

Few markers have displayed the desirable sensitivity and specificity. Ideally such markers would have near $100 \%$ of specificity and high sensitivity. Therefore, the risk of rely on such markers in cases with equivocal diagnoses might result in misdiagnosis and subsequent over or under-treatment of the patients.

Early studies focused on markers that control cellcycle and apoptosis, namely Ki-67, P53, P27, RB (Cryns et al. 1994, Lloyd et al. 1995, Vargas et al. 1997, Cetani et al. 2004b). In more recent years, novel and promising markers have been used including parafibromin, galectin-3, APC and PGP9.5, either as single or panel of markers (Table 3).

Before examining the results of the different studies, it should be kept in mind that there are some limitations in the interpretation of the immunohistochemical stains, namely (i) the lack of a general consensus on the cut-off value of staining to classify the specimens as positive or negative; (ii) the use of various scoring systems; (iii) the use of different immunohistochemistry protocols, including different antibodies and dilution range and (iv) the relative low number of samples. These limitations highly account for the different results among studies published in the literature.

\section{Ki-67}

The cell-cycle-associated Ki-67 antigen is a well-known proliferative index used in several human cancers (Menon et al. 2019). Ki-67 labeling index is mostly reported as the percent of positively stained cells and a cut-off value $>5 \%$ of tumor nuclei stained is commonly accepted as a high proliferative index. Abbona and coworkers firstly used the Ki-67 to successfully differentiate parathyroid carcinomas, especially those with clinically aggressive behavior, from benign tumors (Abbona et al. 1995). Eighty-five percent of specimen diagnosed as atypical adenomas has a Ki-67 proliferative index $<5 \%$ (100/117). Studies on atypical adenomas have shown a variable rate of Ki-67 overexpression ranging from 0 to $67 \%$ (Stojadinovic et al. 2003, Ozolins et al. 2016, Hosny Mohammed et al. 2017) (Table 3). Ozolins and coworkers found that a high Ki-67 expression was of diagnostic value for parathyroid carcinoma, being detected in $87 \%$ of cases compared with $0 \%$ in both benign and atypical adenomas (Ozolins et al. 2016). Similarly, two other studies found an almost exclusive staining in carcinomas (60 and 27\%), being absent in atypical adenomas and only present in 6 and 2\% of benign adenomas (Stojadinovic et al. 2003, Fernandez-Ranvier et al. 2009). A higher expression of $\mathrm{Ki}-67$ in carcinomas (mean value $6.7 \%$, up to $70 \%$ ) as compared to atypical and benign adenomas (mean values $0.3 \%$, up to $2 \%$ and mean value $0.4 \%$, up to $28 \%$ ) was also detected by Kumari and coworkers (Kumari et al. 2016). Other authors did not find any utility of Ki-67 staining to distinguish carcinoma from atypical adenoma (Quinn et al. 2015, Hosny Mohammed et al. 2017). In this regard, one study unexpectedly found low Ki-67 expression both in carcinomas and atypical adenomas (100 and 83\%, respectively) (Karaarslan et al. 2015) (Table 3). When Ki-67 overexpression was combined with galectin-3 overexpression and/or parafibromin loss (see below), the sensitivity and specificity in the differential diagnosis greatly increased (Hosny Mohammed et al. 2017). In summary, the proliferation marker Ki-67 is mainly overexpressed in malignant tumors and appears of limited diagnostic value to distinguish atypical adenomas from carcinomas. (c) 2019 Society for Endocrinology Published by Bioscientifica Ltd. Printed in Great Britain 

mं ㅇํํ

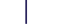

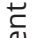

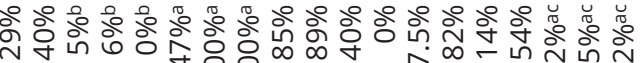

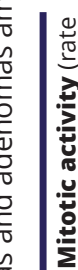
वे

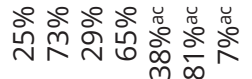

\section{Parafibromin}

Parafibromin is a promising molecular marker for diagnosing parathyroid carcinoma, also confirmed by the evidence in favor of a strong association of CDC73 mutations with malignancy (Cetani et al. 2018). Different criteria have been used to evaluate parafibromin immunostaining among studies. Our group as well as others have defined as negative the complete or diffuse absence of nuclear parafibromin staining in all neoplastic cells in the presence of an internal positive control represented by the endothelial cells within the parathyroid tumors and/or rim of normal parathyroid tissue surrounding the tumor Juhlin et al. 2006, 2007, 2010, Cetani et al. 2007, 2013, Fernandez-Ranvier et al. 2009, Guarnieri et al. 2012, Sulaiman et al. 2012a, Kruijff et al. 2014, Karaarslan et al. 2015). At variance, other authors have regarded partial or focal loss as sufficient to indicate negative staining, providing a higher diagnostic sensitivity as demonstrated by $\mathrm{Hu}$ and coworkers in their meta-analysis (Hu et al. 2016).

Nuclear parafibromin loss (diffuse and/or focal) has been shown in up to $100 \%$ of parathyroid carcinomas in the majority of the studies, and rarely in benign adenomas (up to 13\%) (Juhlin et al. 2006, 2010, Cetani et al. 2007, Guarnieri et al. 2012, Sulaiman et al. 2012a, Kruijff et al. 2014, Quinn et al. 2015, Agarwal et al. 2016, Kumari et al. 2016, Ozolins et al. 2016, Ryhänen et al. 2017) and seems to predict the negative clinical outcome (Cetani et al. 2007, Witteveen et al. 2011) (Table 3). Hu and coworkers conducted a meta-analysis which included ten studies with a total of 202 patients with parathyroid carcinomas. The sensitivity of parafibromin staining ranged from 29 to $100 \%$ and specificity from 61 to $100 \%$. The use of different parafibromin antibody $(P<0.00)$ and scoring criteria $(P<0.05)$ accounted for the difference in sensitivity (Hu et al. 2016).

A significant heterogeneity of the loss of parafibromin staining ranging from 0 to $50 \%$ has been observed in atypical parathyroid adenomas across studies (Table 3). Of note, two studies reported a positive parafibromin expression either in atypical or benign adenomas, and loss of staining was observed in 100 and 31\% of parathyroid carcinomas, respectively, suggesting that atypical adenomas might be considered as benign lesions (Fernandez-Ranvier et al. 2009, Karaarslan et al. 2015). In line with these results, Kruiff and coworkers found that atypical adenomas mostly had a positive staining of parafibromin $(61 \%)$. These authors also showed an apparent cure of the disease in these cases and recurrence 
(10\%) in those with loss of parafibromin staining (Kruijff et al. 2014). On the contrary, Quinn and coworkers and Ryhanen and coworkers did not detect difference in the loss of parafibromin between carcinomas and atypical adenomas ( 38 vs $21 \%, P=0.34$ and 13 vs $4 \%, P=0.34$, respectively) (Quinn et al. 2015, Ryhänen et al. 2017). In the meta-analysis of $\mathrm{Hu}$ and coworkers, 94 patients with atypical parathyroid adenomas were included in six surveys. Meta-regression analysis showed that the inclusion of atypical adenomas in the control group, represented by parathyroid adenomas and hyperplasias, influenced the specificity of parafibromin staining. Indeed, the specificity of parafibromin staining decreased to $63 \%$ if only atypical adenomas were used as control, while it increased to $95 \%$ if other benign lesions were also included (Hu et al. 2016).

Recently, Gill and coworkers reported the results of parafibromin immunohistochemistry in 815 parathyroid tumors of patients undergoing surgery for PHPT during the 12-year period of the study (Gill et al. 2019). The following indications for immunohistochemistry were used: (i) suspected or confirmed parathyroid carcinoma; (ii) atypical parathyroid adenomas; (iii) multiglandular PHPT; (iv) recurrent parathyroid tumors; (v) PHPT at young age; (vi) familiar PHPT with the exclusion of genetic-established syndromic form; (vii) PHPT with severe hypercalcemia; (viii) large size of parathyroid tumors and (ix) operative suspicion of malignancy. They found a complete loss of parafibromin expression in 5.2\% of these tumors, compared to $0.19 \%$ in truly unselected parathyroid tumors included in the study. The authors pointed out that these parafibromin-negative tumors have a distinctive morphology including a sheet-like growth pattern often interrupted by an arborizing vasculature, eosinophilic rather than oxyphilic cytoplasm, nuclear enlargement, speckled chromatin with prominent nucleoli, but relatively preserved nuclei-to-cytoplasm ratio and a characteristic perinuclear cytoplasmic clearing. The authors proposed to consider the parafibromin-negative tumors not fulfilling WHO criteria for malignancy (i.e. adenomas and atypical adenomas) a distinct subtype of parathyroid neoplasms that requires a long-term follow-up because of the risk, although low, of metachronous disease and aggressive behavior (Gill et al. 2019).

Of special note, in addition to its well-known nuclear localization, parafibromin also localizes to the nucleolar compartment. Juhlin and coworkers investigated the expression of nucleolar parafibromin in 16 atypical adenomas and 23 carcinomas. They found that one (6\%) of atypical adenomas and three (13\%) of the carcinomas, which expressed nuclear parafibromin in all or subsets of the tumor cells, did not display the protein at nucleolar level (Juhlin et al. 2011). Remarkably, all three carcinomas but not the atypical adenoma harbored CDC73 mutations which predicted the loss of the three nucleolar localization signals of parafibromin. The authors suggested that the search for nucleolar staining might increase the sensitivity for the detection of carcinoma and atypical adenoma in cases positive to nuclear parafibromin, compared to the search for nuclear parafibromin alone. Very recently, the same authors published an additional study on nucleolar parafibromin immunostaining (Juhlin et al. 2019). Three of $46(6.5 \%)$ atypical adenomas displayed loss of nucleolar parafibromin expression, confirming the previous results obtained in a smaller cohort of atypical adenomas (Juhlin et al. 2011). The lack of CDC73 mutational status of samples with negative nucleolar staining raise the question of whether this staining pattern might be of relevance in the clinical practice. Indeed, the authors have acknowledged that the significance of the presence or loss of nucleolar expression is currently of uncertain significance and no other researchers have investigated the nucleolar localization of parafibromin.

\section{Adenomatous polyposis coli}

Adenomatous polyposis coli (APC) is a ubiquitously expressed tumor suppressor protein that acts as an antagonist of the Wnt signaling pathway, regulating $\beta$-catenin concentrations and interacting with E-cadherin. APC is uniformly expressed in normal parathyroid tissue and adenomas, and loss of APC expression has been observed in up to 100\% of carcinomas (Juhlin et al. 2006, 2010). Loss of APC in atypical adenomas ranges between $23 \%$ and $67 \%$ of cases among the studies (Table 3). Its role as a tool for help differentiating parathyroid neoplasms is of limited value because of the overlap in the loss of APC expression between benign and malignant lesions (Agarwal et al. 2016, Kumari et al. 2016).

\section{Galectin-3}

Galectin-3 is a member of the lectin family and is involved in regulatory functions critical in cancer such as apoptosis, angiogenesis, metastasis, immune surveillance, gene expression and inflammation. Galectin-3 overexpression seems to be related to the ability of the tumor to evade apoptosis. Galectin-3 was firstly studied in parathyroid tumors by Bergero and coworkers who found a diffuse overexpression in $>90 \%(24 / 26)$ of parathyroid carcinomas 
(metastatic or not) and in only 3\% (1/30) of adenomas, highly suggesting that galectin-3 could be a marker in the differential diagnosis between benign and malignant parathyroid tumors (Bergero et al. 2005).

Galectin-3 expression has been evaluated in 56 atypical parathyroid adenomas either alone or combined with other markers (Table 3). Galectin-3 overexpression (range 32-100\%) was found at a rate similar to that observed in parathyroid carcinoma, indicating that this marker, when used alone, does not help to differentiate these two categories of parathyroid neoplasms (Table 3). In contrast, galectin-3 overexpression is rarely found in benign parathyroid adenoma (Kumari et al. 2016). Of note, Karaaslan and coworkers found a significant difference in the percentage of diffuse staining (>30\% extent of staining) of galectin-3 between carcinomas, atypical adenomas and adenomas, but when considering the presence of focal positivity ( $\leq 30 \%$ extent of staining) alone, the distinction between the three groups was no more seen (Karaarslan et al. 2015).

\section{Protein gene product 9.5 (PGP9.5)}

PGP9.5 is the product of ubiquitin carboxyl-terminal esterase L1 (UCHL1) gene. Its expression is highly specific to neurons and cells of the neuroendocrine system and their tumors. PGP9.5 is also expressed during embryonic development of the parathyroid glands in the rat. Marked overexpression has been reported in some cancers (nonsmall-cell lung, colon-rectal, esophageal, gastric, prostate and hepatocellular cancers) and has been associated with advanced staging. PGP9.5 overexpression has been found as a statistically significant classifier for carcinomas and HPT-JT-associated tumors (Haven et al. 2004, Howell et al. 2009). PGP9.5 overexpression in atypical parathyroid adenomas ranges between 22 and 35\%, whereas in carcinomas between 35 and 71\% (Howell et al. 2009, Kruijff et al. 2014, Truran et al. 2014, Agarwal et al. 2016, Kumari et al. 2016). Conversely, in benign adenomas PGP9.5 overexpression ranges from 0 and 22\% (Howell et al. 2009, Truran et al. 2014, Agarwal et al. 2016, Kumari et al. 2016) (Table 3). PGP9.5 overexpression was the strongest predictor for recurrent hypercalcemia after the first operation either in atypical adenomas or carcinomas $(P=0.003)$ (Kruijff et al. 2014).

\section{Panels of immunohistochemical markers}

In addition to studies evaluating the expression of single immunohistochemical markers, the pathological evaluation of parathyroid lesions may benefit from the use of a combination of multiple markers (Table 3). As a matter of fact, a panel of markers may better characterize the complexity of the molecular alterations in the context of the same neoplastic lesion.

Stojadinovic and coworkers firstly used a panel of markers focused on proteins involved in cell-cycle regulation and affecting cell proliferation (P53, mdm2, P21, P27, cyclin D1, Ki-67 and BCL2) in a cohort of 8 atypical adenomas, 20 carcinomas and 45 benign adenomas (Stojadinovic et al. 2003). The authors found that P53 was indiscriminately negative across the different categories of tumors (Stojadinovic et al. 2003). Conversely, previous studies detected P53 overexpression in up to $52 \%$ of benign parathyroid adenomas and $22 \%$ of carcinomas (Cryns et al. 1994, Kishikawa et al. 1999, Stojadinovic et al. 2003). Therefore, excluding P53 from the panel, they found that atypical parathyroid adenomas had mostly overlapping molecular profiles, either with the benign counterpart or carcinoma. The phenotype P27(+) BCL-2(+) Ki-67(-) MDM2(+) was typical of non-malignant tumors being present in adenomas (76\% in typical and 29\% atypical adenomas) but absent in carcinomas, suggesting that this profile might be useful to distinguish benign from malignant neoplasms. Nonetheless, no distinctive molecular profile was exclusively associated with parathyroid atypical adenomas (Stojadinovic et al. 2003).

Expression of parafibromin, RB, galectin-3, Ki-67, P27 and MDM2 was investigated in parathyroid carcinomas, atypical adenomas and benign neoplasms with a tissue microarray technique (Fernandez-Ranvier et al. 2009). The loss of parafibromin and RB expression, associated with galectin-3 and Ki-67 overexpression, could differentiate parathyroid carcinoma from other parathyroid tumors, including atypical adenomas, which displayed a profile of benign tumors. Conversely, the expression of both P27 and MDM2 proteins was heterogeneous among the different categories. Of note, this study included only two cases of atypical adenomas and therefore no conclusions on the utility of these immunohistochemical panels can be drawn (Fernandez-Ranvier et al. 2009).

Juhlin and coworkers showed that loss of APC expression associated with a reduced expression of parafibromin was common in atypical or malignant tumors (Juhlin et al. 2010). Loss of parafibromin but not of APC was also found in a few benign adenomas, suggesting that APC seems to be preferred to parafibromin in the differential diagnosis of malignant tumors for its higher specificity. 
A panel consisting of parafibromin, APC, galectin-3 and PGP9.5 was investigated in two studies (Agarwal et al. 2016, Kumari et al. 2016). An intermediate level of immunostaining for each single marker was detected in atypical adenomas compared to carcinomas and adenomas (Table 3). No association was found in the various combined immunoprofile between atypical and benign adenomas in a subgroup of specimen selected for having a gland size $>10 \mathrm{~g}$ (Agarwal et al. 2016). However, Agarwal and coworkers showed that parafibromin loss segregated with atypical parathyroid adenomas, suggesting that such tumors might be prone to malignant progression (Agarwal et al. 2016). Conversely, Kumari and coworkers reaffirmed the importance of histology as a diagnostic tool for predicting a malignant behavior of parathyroid tumors. They suggested that the combination of positive staining for parafibromin and negative staining for PGP9.5 and/ or galectin-3 could be associated with a positive outcome in atypical parathyroid adenoma and carcinoma, and proposed to consider them as a benign neoplasm or a cancer with low-risk of recurrence, respectively (Kumari et al. 2016).

Karaaslan and coworkers evaluated the immunostaining of parafibromin, galectin-3, Ki-67 and Hector Battifora mesothelial cell-1 (HBME-1), a common molecular marker of tumors mostly used as a diagnostic and prognostic tool for thyroid carcinoma. The latter marker was not informative, whereas the finding of retained parafibromin expression associated with galectin-3 negative or weak positive immunostaining and a Ki-67 proliferation index $<1 \%$ was the signature of benign adenoma, but not of carcinoma and atypical adenoma (Karaarslan et al. 2015).

\section{Additional immunohistochemical markers}

Calcium-sensing receptor (CASR) has been evaluated in 14 atypical adenomas in comparison with 21 carcinomas and 10 adenomas (Sungu et al. 2018). A global loss of CASR was detected in 7\% of atypical adenomas and $50 \%$ of carcinoma and in any adenomas, suggesting that CASR might be of help in distinguishing carcinomas from adenomas (either atypical or benign adenoma) (Sungu et al. 2018). In line with these results, loss of CASR protein was previously reported in about $30 \%$ of sporadic parathyroid carcinomas and was associated with a worse prognosis of the patients (Haven et al. 2004, Witteveen et al. 2011).
Overexpression of cyclin D1 has been reported in about $65-90 \%$ of parathyroid carcinomas and in $18-40 \%$ of benign adenomas (Brewer et al. 2019). Conversely, its overexpression in atypical adenomas ranges between 13 and 71\% (Stojadinovic et al. 2003, Cetani et al. 2007, Sungu et al. 2018). The variability of results among the different categories of parathyroid tumors suggests that this marker has a limited diagnostic role (Table 3).

A strong membranous staining of E-cadherin has been detected in benign parathyroid tumors, and its loss has a key role in the tumorigenesis of parathyroid carcinomas and other malignancies (Fendrich et al. 2009). Membranous distribution pattern of E-cadherin was found in 14/16 (87.5\%) and a mixed membranous and cytoplasmatic distribution in 2/16 atypical adenomas (Schneider et al. 2015). During the follow-up (median 30 months), all but one patients were cured.

Estrogen receptor (ER) signaling is associated with tumorigenesis of different tissues, where loss of ERB1 is associated with a worse prognosis. No statistical difference in the intensity of nuclear estrogen receptor $\beta$ type 1 (ERB1) and 2 (ERB2) staining has been detected in atypical adenomas $(n=7)$ compared with carcinomas $(n=6)$, benign adenomas $(n=161)$, normal parathyroid gland and tumor rims (Haglund et al. 2015). An inverse correlation between ERB1 expression level and tumor weight was found.

No difference in the expression level of programmed death-ligand 1 (PD-L1), a transmembrane protein expressed in several normal tissues and immune cells and involved in the interaction of tumor cells with host immune response, was observed between atypical adenomas and carcinomas (Silva-Figueroa et al. 2018). In this study, the authors also investigated the tumor-infiltrating lymphocytes (CD3+ and $\left.\mathrm{CD} 8^{+}\right)$and macrophages (CD68+). Atypical adenomas displayed a significant greater expression of CD3 compared with carcinomas, whereas there was no difference in the densities of CD8 and CD68 between groups, although parathyroid carcinomas showed a greater expression of CD68 compared with atypical adenomas, suggesting that the macrophage inflammatory process might be a potential contributor to disease aggressiveness. The authors concluded that $\mathrm{CD}^{+}$ might represent a novel promising biomarker useful to differentiate atypical adenomas from carcinomas.

An accumulation of alpha-smooth muscle actin $(\alpha$-SMA), a marker of activated fibroblasts, was observed in fibrous bands and capsule in atypical adenomas $(n=5)$ and carcinomas $(n=4)$ but also in the
C) 2019 Society for Endocrinology Published by Bioscientifica Ltd. Printed in Great Britain 
parenchyma of adenomas and normal parathyroid glands (Verdelli et al. 2015).

Telomerase activation is implicated in human cancer progression and shown to represent a specific feature of parathyroid carcinoma but not of parathyroid adenoma (Onoda et al. 2004). Osawa and coworkers investigated the nuclear staining of human telomerase reverse transcriptase (hTERT), the catalytic subunit bearing the enzymatic activity of telomerase, in different parathyroid neoplasms (Osawa et al. 2009). They found that one typical parathyroid adenoma showed a positive staining either in the primary tumor or in two recurrent parathyroid tissues of the same patient whereas no staining was observed in benign adenomas and four normal parathyroid glands. Conversely, all six carcinomas had positive nuclear staining.

A diffuse nuclear expression of glial cells missing 2 (GCM2), a transcription factor exclusively expressed in the parathyroid gland, was shown in normal parathyroid glands and 58 benign and malignant tumors, including two atypical parathyroid adenomas, without difference among parathyroid lesions (Nonaka 2011).

Alterations of some proteins involved in the Wnt/ $\beta$-catenin signaling may lead to nuclear accumulation of $\beta$-catenin and activation of gene transcription. Nuclear accumulation of active unphosphorilated $\beta$-catenin has been reported by some authors in parathyroid carcinoma and parathyroid adenoma (Björklund et al. 2008, Svedlund et al. 2010). We studied the staining of nuclear $\beta$-catenin in three atypical adenomas, 18 carcinomas and 63 adenomas (Cetani et al. 2010). In agreement with other authors, all tumors were immune negative, suggesting that $\beta$-catenin immunostaining is not useful in the differential diagnosis of these neoplasms (Cetani et al. 2010).

\section{Clinical profile}

The presenting symptoms and signs include symptomatic nephrolithiasis, fatigue, bone pain, brown tumor and depression. Notably, none of these signs are specific for patients with atypical parathyroid adenoma. Renal manifestations (nephrocalcinosis, nephrolithiasis and kidney failure) occur in $29 \%$ of patients, bone involvement (osteititis fibrosa cystica, osteoporosis and pathological fractures) in $18 \%$ and both manifestations in $3 \%$ of cases. On physical examination, 15\% of patients with atypical adenomas have a palpable neck lesion (Table 1 and Supplementary Table 1 , see section on supplementary data given at the end of this article), but a higher rate (32\%) has been reported in the cohort of Quinn et al. (2015). Yener and coworkers described the unique patient with atypical adenoma presenting with spontaneous tendon rupture, a rare presentation of PHPT (Yener et al. 2014).

The biochemical profile of patients with atypical parathyroid adenoma is more similar to that of patients with carcinoma than classic adenoma and is characterized by moderate hypercalcemia (median $12.9 \mathrm{mg} / \mathrm{dL}$ ) associated with elevated PTH levels (mean values 12 times above the upper value of normal range) (Table 1).

Most parathyroid tumors are solid, but a few of them can be cystic or partly cystic. In a cohort of 907 patients with benign and atypical parathyroid adenomas, $\mathrm{Hu}$ and coworkers found an incidence of $4 \%$ of cystic parathyroid adenomas, based on ultrasound or pathology (Hu et al. 2018). The authors defined parathyroid lesion as cystic when the cystic areas occupied more than $50 \%$ of the estimated volume of the parathyroid gland. Interestingly, atypical adenomas $(n=56)$ were more common among cystic rather than solid lesions $(9 / 37,24.3 \%$ vs $47 / 870$, $5.4 \%, P=0.001$ ) (Hu et al. 2018). The overall data of the literature reported a frequency of $30 \%$ of cystic atypical parathyroid adenomas based on imaging and/or pathology, $86 \%$ of them were found at histology (Table 1 and Supplementary Table 1).

At surgery, a firm and/or adherent lesion to the neighboring tissues, which can raise the suspicion of malignancy, may be found in up to $74 \%$ of the patients (Schneider et al. 2015) (Supplementary Table 1). Taking into account all studies evaluating the presence of adherence, it has been described in $43 \%$ of cases (Table 1). Christakis and coworkers, in a series of 23 atypical adenomas and 31 carcinomas, reported a higher rate of pre-operative (clinical, biochemical and imaging) or intraoperative features of malignancy in the latter compared to the former ( $P=0.023$ and $P=0.006$, respectively). The presence of adherence to adjacent structures was the best intraoperative predictor of carcinoma $(P=0.033)$ (Christakis et al. 2016).

About one quarter of patients with the histological diagnosis of atypical parathyroid adenoma undergo en bloc resection mostly based on operative findings (macroscopic aspect of the tumor and/or presence of adherence to adjacent structures). The remaining patients undergo bilateral exploration and/or mininvasive parathyroidectomy (PTx). Ectopic parathyroid adenomas account for $4-22 \%$ in different case series (Phitayakorn \& McHenry 2006, Roy et al. 2013). Of note, five were at ectopic sites $(1.8 \%)$, mainly in the anterior mediastinum (Table 1) (Pal et al. 2018). 
The median size and weight of atypical parathyroid adenomas are $2.5 \mathrm{~cm}$ (range $0.7-7.2 \mathrm{~cm}$ ) and $4.15 \mathrm{~g}$ (range $0.3-101 \mathrm{~g}$ ), respectively (Table 1). Agarwal and coworkers found that atypical adenomas were more common in tumors weighing $\geq 7 \mathrm{~g}(20.4 \%)$ than in those $<7 \mathrm{~g}(6.9 \%)$ and that the incidence of atypia reached $33 \%$ in tumors $\geq 10 \mathrm{~g}$ (Agarwal et al. 2016). Similarly, $\mathrm{O}^{\prime} \mathrm{Neal}$ and coworkers found that the rate of atypical parathyroid adenomas was significantly higher than that of carcinomas among tumors weighting $\geq 2 \mathrm{~g}$ $(17.5$ vs $1.3 \%, P<0.05)\left(\mathrm{O}^{\prime}\right.$ Neal et al. 2011). Nevertheless, one study found a higher rate of large tumor, based on diameters measured by pre-operative neck ultrasound, in the groups of atypical parathyroid adenoma and carcinoma than in classical adenoma group $(P<0.001)$ (Cakir et al. 2016).

Despite the more severe clinical and biochemical profile of patients with atypical adenomas, compared with that with benign disease, most patients (96\%) are cured with PTx. However, a note of caution should be taken into account since the median follow-up is rather short (median 47 (0.25-252) months) (Table 1).

The overall rate of recurrence of atypical parathyroid adenomas is 3\% and is higher in familial than in sporadic cases (40 vs $2 \%, P<0.0001)$ (Table 1$)$. The interval between the initial PTx and the first recurrence of tumor ranged from 12 months to 17 years (mean 101 months) (Supplementary Table 1).

Survival data derived from longitudinal retrospective studies at single institutions found an overall survival up to $93 \%$ after a follow-up of 5 and 10 years (Christakis et al. 2016, Ryhänen et al. 2017). However, all deaths were unrelated to the disease.

\section{Impact of molecular and immunohistochemical profile on outcome}

Few studies have reported data on the impact of molecular profile on clinical outcome of patients with atypical adenomas so far (Table 2). These studies were mainly focused on CDC73 mutations. Of note, $42 \%$ of patients carrying germline $C D C 73$ had recurrence and/or persistence of disease after a median and mean follow-up of 120 (range 23-252) and $110 \pm 71$ months, respectively (Table 2). The only patient carrying a somatic CDC73 mutation was cured after a 120-month follow-up. Ninetyfive percent of $C D C 73$ mutation-negative patients were cured by surgery.
The impact of immunohistochemical markers on the outcome of patients having an atypical parathyroid adenoma has also been evaluated in few studies with discrepant results. As to whether parafibromin staining may predict the recurrence risk of atypical adenomas and therefore classify the tumors as having low or high malignant potential has been one of the main aims of the studies. One of the first study addressing this issue was published in 2013 and included 54 atypical adenomas (Kruijff et al. 2014). The authors were able of demonstrating that patients with parafibromin-positive tumors had no risk of recurrence whereas the only two cases $(10 \%)$ with recurrence had loss of parafibromin expression. The authors suggested that patients with atypical adenomas with retained parafibromin expression should be managed as tumor having a benign behavior, whereas those with loss of parafibromin expression have a real, even if low, risk of recurrence, and should be classified as tumors of low malignant potential (Kruijff et al. 2014). At variance with these results, Agarwal and coworkers found loss of parafibromin staining in $8 / 22$ (36\%) patients with large atypical parathyroid adenomas $(\geq 7 \mathrm{~g})$ and none had recurrence of the disease after a median follow-up of 40 months (Agarwal et al. 2016). All patients whose tumors were parafibromin positive were also cured by PTx.

When we considered the overall studies on parafibromin immunostaining that included the outcome of the patients only seven were selected. Data on parafibromin staining are available in 130 patients with atypical parathyroid adenoma with a follow-up ranging between 1 and 210 months. Loss of parafibromin expression was observed in $40(31 \%)$ cases and the recurrence rate did not differ between patients with retained or lost parafibromin expression (4 vs 12.5\%, respectively; $P=0.135$ ) (Cetani et al. 2007, FernandezRanvier et al. 2009, Guarnieri et al. 2012, Kruijff et al. 2014, Agarwal et al. 2016, Kumari et al. 2016, Ryhänen et al. 2017).

\section{Additional clinical considerations and surveillance}

The diagnosis of atypical parathyroid adenomas should always be performed by an expert parathyroid pathologist because of the challenge in distinguishing parathyroid atypical adenoma from carcinoma. In our opinion, the histological slides should always be reviewed when https://erc bioscientifica.com

https://doi.org/10.1530/ERC-19-0135 (c) 2019 Society for Endocrinology Published by Bioscientifica Ltd. Printed in Great Britain 
the initial diagnosis was made by an inexperienced parathyroid pathologist. Once the histopathological diagnosis has been confirmed, parafibromin immunohistochemistry should be carried out, as suggested by other authors (Cardoso et al. 2017, Van Der Tuin et al. 2017), together with the germline testing of CDC73 gene. Conversely, Gill and coworkers suggested that for atypical adenomas without concerning clinical features of family history the genetic screening should only be performed in patients with parafibromin loss (Gill et al. 2019).

When a CDC73 germline mutation is identified, the genetic testing should be offered to first-degree relatives, even if asymptomatic, to identify mutation carriers who are at high risk of developing HPT-JT-associated tumors. At the same time, the identification of relatives not carrying the CDC73 mutation would allow reassuring them from the anxiety of developing the disease and prevent unnecessary screening.

No specific guidelines for the surveillance of patients with atypical parathyroid adenomas after parathyroid surgery exist so far. Some authors, based on their own experience, suggest a close follow-up for the risk, although low, of recurrence, regardless of the results of immunostaining (Kumari et al. 2016, $\mathrm{Hu}$ et al. 2018). Conversely, others advise a close follow-up only in patients with atypical tumors of large size and/or complete loss of parafibromin expression (Kruijff et al. 2014, Agarwal et al. 2016, Ryhänen et al. 2017, Gill et al. 2019).

At our institution, regardless of the results of parafibromin immunostaining, we recommend annual follow-up evaluations including biochemical testing and neck ultrasound for the first 5 years after initial surgery and every 2-3 years thereafter. An appropriate screening for $C D C 73$-related tumors is also recommended in patients carrying germline CDC73 mutations.

\section{Conclusions}

The diagnosis of atypical adenoma is still challenging. On the basis of studies reported in the literature, patients with atypical parathyroid adenoma at diagnosis have a clinical and biochemical profile more severe that the benign counterpart and, to some extent, similar even though less severe, to that of patients with parathyroid carcinoma. The molecular signature of these neoplasms is still unknown and the germline CDC73 mutations appears to be the most common anomaly in this setting suggesting that these cases might represent HPT-JT variants. This latter finding should prompt a genetic analysis in first-degree relatives. No specific immunohistochemical signature has currently been identified. Despite the lack of prospective studies the outcome of patients with atypical parathyroid adenomas is benign in the majority of cases.

\section{Future directions}

A collaborative approach aimed to collect data on a large number of patients with atypical parathyroid adenoma is required to increase our knowledge on the molecular profile of the disease. A modern approach using whole exome sequencing of somatic and germline DNA samples could lead to the identification of a specific genetic signature of patients who are at risk of recurrence and guide an adequate postoperative monitoring and, at the same time, relieve of the anxiety of a relatively strict monitoring of patients not at risk.

\section{Supplementary data}

This is linked to the online version of the paper at https://doi.org/10.1530/ ERC-19-0135.

\section{Declaration of interest}

The authors declare that there is no conflict of interest that could be perceived as prejudicing the impartiality of this review.

\section{Funding}

This work did not receive any specific grant from any funding agency in the public, commercial, or not-for-profit sector.

\section{Author contribution statement}

Filomena Cetani and Elena Pardi collected all the data from literature, conceived the work and wrote the manuscript. Liborio Torregrossa wrote and supervised the part related to pathological and immunohistochemical features. Claudio Marcocci proofread the manuscript.

\section{Acknowledgments}

The authors wish to thank Simona Borsari for reading the manuscript.

\section{References}

Abbona GC, Papotti M, Gasparri G \& Bussolati G 1995 Proliferative activity in parathyroid tumors as detected by Ki-67 immunostaining. Human Pathology 26 135-138. (https://doi.org/10.1016/00468177(95)90028-4)
(C) 2019 Society for Endocrinology Published by Bioscientifica Ltd. Printed in Great Britain 
Agarwal A, Pradhan R, Kumari N, Krishnani N, Shukla P, Gupta SK, Chand G, Mishra A, Agarwal G, Verma AK, et al. 2016 Molecular characteristics of large parathyroid adenomas. World Journal of Surgery 40 607-614. (https://doi.org/10.1007/s00268-015-3380-2)

Barazeghi E, Gill AJ, Sidhu S, Norlén O, Dina R, Palazzo FF, Hellman P, Stålberg P \& Westin G 2016 5-Hydroxymethylcytosine discriminates between parathyroid adenoma and carcinoma. Clinical Epigenetics $\mathbf{8}$ 31. (https://doi.org/10.1186/s13148-016-0197-2)

Bergero N, De Pompa R, Sacerdote C, Gasparri G, Volante M, Bussolati G \& Papotti M 2005 Galectin-3 expression in parathyroid carcinoma: immunohistochemical study of 26 cases. Human Pathology 36 908-914.. (https://doi.org/10.1016/j.humpath.2005.06.020)

Bilezikian JP, Bandeira L, Khan A \& Cusano NE 2018 Hyperparathyroidism. Lancet 391 168-178. (https://doi.org/10.1016/ S0140-6736(17)31430-7)

Björklund P, Lindberg D, Åkerström G \& Westin G 2008 Stabilizing mutation of CTNNB1/beta-catenin and protein accumulation analyzed in a large series of parathyroid tumors of Swedish patients. Molecular Cancer 7 1-8. (https://doi.org/10.1186/14764598-7-53)

Bondenson L, Sandelin K \& Grimelius L 1993 Histopathological variables and DNA cytometry in parathyroid carcinoma. American Journal of Surgical Pathology 17 820-829. (https://doi. org/10.1097/00000478-199308000-00007)

Bradley KJ, Cavaco BM, Bowl MR, Harding B, Young A \& Thakker RV 2005 Utilisation of a cryptic non-canonical donor splice site of the gene encoding PARAFIBROMIN is associated with familial isolated primary hyperparathyroidism. Journal of Medical Genetics 42 e51. (https://doi.org/10.1136/jmg.2005.032201)

Bradley KJ, Cavaco BM, Bowl MR, Harding B, Cranston T, Fratter C, Besser GM, Conceicao Pereira M, Davie MWJ, Dudley N, et al. 2006 Parafibromin mutations in hereditary hyperparathyroidism syndromes and parathyroid tumours. Clinical Endocrinology 64 299-306. (https://doi.org/10.1111/j.1365-2265.2006.02460.x)

Brewer K, Costa-Guda J \& Arnold A 2019 Molecular genetic insights into sporadic primary hyperparathyroidism. Endocrine-Related Cancer $\mathbf{2 6}$ R53-R72. (https://doi.org/10.1530/ERC-18-0304)

Bricaire L, Odou M, Cardot-Bauters C, Delemer B, North M-O, Salenave S, Vezzosi D, Kuhn J-M, Murat A, Caron P, et al. 2013 Frequent large germline HRPT2 deletions in a French national cohort of patients with primary hyperparathyroidism. Journal of Clinical Endocrinolgy and Metabolism 98 E403-E408. (https://doi. org/10.1210/jc.2012-2789)

Cakir B, Polat SB, Kilic M, Ozdemir D, Aydin C, Süngü N \& Ersoy R 2016 Evaluation of preoperative ultrasonographic and biochemical features of patients with aggressive parathyroid disease: is there a reliable predictive marker? Archives of Endocrinology and Metabolism 60 537-544. (https://doi. org/10.1590/2359-3997000000224)

Cardoso L, Stevenson M \& Thakker RV 2017 Molecular genetics of syndromic and non-syndromic forms of parathyroid carcinoma. Human Mutation 38 1621-1648. (https://doi.org/10.1002/ humu.23337)

Carpten JD, Robbins CM, Villablanca A, Forsberg L, Presciuttini S, Bailey-Wilson J, Simonds WF, Gillanders EM, Kennedy AM, Chen JD, et al. 2002 HRPT2, encoding parafibromin, is mutated in hyperparathyroidism-jaw tumor syndrome. Nature Genetics $\mathbf{3 2}$ 676-680. (https://doi.org/10.1038/ng1048)

Cavaco BM, Guerra L, Bradley KJ, Carvalho D, Harding B, Oliveira A, Santos MA, Sobrinho LG, Thakker RV. \& Leite V 2004 Hyperparathyroidism-jaw tumor syndrome in Roma families from Portugal is due to a founder mutation of the HRPT2 gene. Journal of Clinical Endocrinology and Metabolism 89 1747-1752. (https://doi. org/10.1210/jc.2003-031016)

Cetani F, Pinchera A, Pardi E, Cianferotti L, Vignali E, Picone A, Miccoli P, Viacava P \& Marcocci C 1999 No evidence for mutations in the calcium-sensing receptor gene in sporadic parathyroid adenomas. Journal of Bone and Mineral Research 14 878-882. (https:// doi.org/10.1359/jbmr.1999.14.6.878)

Cetani F, Pardi E, Giovannetti A, Vignali E, Borsari S, Golia F, Cianferotti L, Viacava P, Miccoli P, Gasperi M, et al. 2002 Genetic analysis of the MEN1 gene and HPRT2 locus in two Italian kindreds with familial isolated hyperparathyroidism. Clinical Endocrinology 56 457-464. (https://doi. org/10.1046/j.1365-2265.2002.01502.x)

Cetani F, Pardi E, Borsari S, Viacava P, Dipollina G, Cianferotti L, Ambrogini E, Gazzerro E, Colussi G, Berti P, et al. 2004a Genetic analyses of the HRPT2 gene in primary hyperparathyroidism: germline and somatic mutations in familial and sporadic parathyroid tumors. Journal of Clinical Endocrinology and Metabolism $\mathbf{8 9}$ 5583-5591. (https://doi.org/10.1210/jc.2004-0294)

Cetani F, Pardi E, Viacava P, Di Pollina GD, Fanelli G, Picone A, Borsari S, Gazzerro E, Miccoli P, Berti P, et al. 2004b A reappraisal of the $\mathrm{Rb} 1$ gene abnormalities in the diagnosis of parathyroid cancer. Clinical Endocrinology 60 99-106. (https://doi. org/10.1111/j.1365-2265.2004.01954.x)

Cetani F, Ambrogini E, Viacava P, Pardi E, Fanelli G, Naccarato AG, Borsari S, Lemmi M, Berti P, Miccoli P, et al. 2007 Should parafibromin staining replace HRTP2 gene analysis as an additional tool for histologic diagnosis of parathyroid carcinoma? European Journal of Endocrinology 156 547-554. (https://doi.org/10.1530/EJE06-0720)

Cetani F, Picone A, Cerrai P, Vignali E, Borsari S, Pardi E, Viacava P, Naccarato AG, Miccoli P, Kifor O, et al. 2008 Parathyroid expression of calcium-sensing receptor point in patients with primary hyperparathyroidism. Journal of Clinical Endocrinology and Metabolism 85 4789-4794. (https://doi.or/10.1210/ jcem.85.12.7028)

Cetani F, Pardi E, Banti C, Collecchi P, Viacava P, Borsari S, Fanelli G, Naccarato AG, Saponaro F, Berti P, et al. 2010 B-catenin activation is not involved in sporadic parathyroid carcinomas and adenomas. Endocrine-Related Cancer 17 1-6. (https://doi.org/10.1677/ERC-090147)

Cetani F, Banti C, Pardi E, Borsari S, Viacava P, Miccoli P, Torregrossa L, Basolo F, Pelizzo MR, Rugge M, et al. 2013 CDC73 mutational status and loss of parafibromin in the outcome of parathyroid cancer. Endocrine Connections 2 186-195. (https://doi.org/10.1530/EC-130046)

Cetani F, Pardi E \& Marcocci C 2016 Update on parathyroid carcinoma. Journal of Endocrinological Investigation 39 595-606. (https://doi. org/10.1007/s40618-016-0447-3)

Cetani F, Pardi E \& Marcocci C 2018 Parathyroid carcinoma: a clinical and genetic perspective. Minerva Endocrinologica 43 144-155. (https://doi.org/10.23736/S0391-1977.17.02737-7)

Chan J 2007 Tumors of thyroid and parathyroid glands. In Diagnostic Histopathology of Tumors, 2nd ed., vol. 2, pp 959-1056. Eds C Fletcher. London, UK: Churchill Livingstone.

Chandramohan A, Sathyakumar K, John RA, Manipadam MT, Abraham D, Paul TV, Thomas N \& Paul MJ 2014 Atypical ultrasound features of parathyroid tumours may bear a relationship to their clinical and biochemical presentation. Insights into Imaging 5 103-111. (https://doi.org/10.1007/s13244-013-0297-x)

Christakis I, Bussaidy N, Clarke C, Kwatampora LJ, Warneke CL, Silva AM, Williams MD, Grubbs EG, Lee JE \& Perrier ND 2016 Differentiating atypical parathyroid neoplasm from parathyroid cancer. Annals of Surgical Oncology 23 2889-2897. (https://doi. org/10.1245/s10434-016-5248-6)

Costa-Guda J, Imanishi Y, Palanisamy N, Kawamata N, Phillip Koeffler H, Chaganti RSK \& Arnold A 2013 Allelic imbalance in sporadic parathyroid carcinoma and evidence for its de novo origins. Endocrine 44 489-495. (https://doi.org/10.1007/s12020013-9903-4) https://erc.bioscientifica.com

https://doi.org/10.1530/ERC-19-0135 (c) 2019 Society for Endocrinology Published by Bioscientifica Ltd. Printed in Great Britain 
Cromer MK, Starker LF, Choi M, Udelsman R, Nelson-Williams C, Lifton RP \& Carling T 2012 Identification of somatic mutations in parathyroid tumors using whole-exome sequencing. Journal of Clinical Endocrinology and Metabolism 97 E1774-E1781. (https://doi. org/10.1210/jc.2012-1743)

Cryns VL, Thor A, Xu HJ, Hu SX, Wierman ME, Vickery AL, Benedict WF \& Arnold A 1994 Loss of the retinoblastoma tumorsuppressor gene in parathyroid carcinoma. New England Journal of Medicine 330 757-761. (https://doi.org/10.1056/ NEJM199403173301105)

de Meneses Montenegro FL, Tavares MR, Durazzo MD, Cernea CR, Cordeiro AC \& Ferras AR 2006 Clinical suspicion and parathyroid carcinoma management. Sao Paulo Medical Journal 124 42-44. (https://doi.org/10.1590/S1516-31802006000100009)

DeLellis RA 2008 Challenging lesions in the differential diagnosis of endocrine tumors: parathryoid carcinoma. Endocrine Pathology 19 221-225. (https://doi.org/10.1007/s12022-008-9050-2)

Delellis RA 2011 Parathyroid tumors and related disorders. Modern Pathology 24 S78-S93. (https://doi.org/10.1038/modpathol.2010.132)

DeLellis R, Lloyd R, Heitz P \& Eng C 2004 Pathology and Genetics. Tumors of Endocrine Organs. WHO Classification of Tumours. Lyon, France: IARC Press.

DeLellis R, Larsson C, Arnold A, Lloy R, Bilezikian J, Mete O \& Eng C 2017 Tumors of the parathyroid glands. In WHO Classification of Tumors of Endocrine Organs, 4th ed., pp 145-159. Eds R Lloyd, R Osamura, G Kloppel \& J Rosai. Lyon, France: IARC Press.

Demiralay E, Altaca G, \& Demirhan B 2011 Morphological evaluation of parathyroid adenomas and immunohistochemical analysis of Pcna and Ki-67 proliferation markers. Turkish Journal of Pathology $\mathbf{2 7}$ 215-220. (https://doi.org/10.5146/tjpath.2011.01078)

Fendrich V, Waldmann J, Feldmann G, Schlosser K, König A, Ramaswamy A, Bartsch DK \& Karakas E 2009 Unique expression pattern of the EMT markers Snail, Twist and E-cadherin in benign and malignant parathyroid neoplasia. European Journal of Endocrinology 160 695-703. (https://doi.org/10.1530/EJE-08-0662)

Fernandez-Ranvier GG, Khanafshar E, Jensen K, Zarnegar R, Lee J, Kebebew E, Dun QY \& Clark OH 2007 Parathyroid carcinoma, atypical parathyroid adenoma, or parathyromatosis? Cancer 110 255-264. (https://doi.org/10.1002/cncr.22790)

Fernandez-Ranvier GG, Khanafshar E, Tacha D, Wong M, Kebebew E, Duh QY \& Clark OH 2009 Defining a molecular phenotype for benign and malignant parathyroid tumors. Cancer $115334-344$. (https://doi.org/10.1002/cncr.24037)

Gill AJ, Lim G, Cheung VKY, Andrici J, Perry-keene JL, Paik J, Sioson L, Clarkson A, Sheen A, Luxford C, et al. 2019 Parafibromin-deficient (HPT-JT type, CDC73 mutated) parathyroid tumors demonstrate distinctive morphologic features. American Journal of Surgical Pathology 43 35-46. (https://doi.org/10.1097/

PAS.0000000000001017)

Guarnieri V, Canaff L, Yun FHJ, Scillitani A, Battista C, Muscarella LA, Wong BYL, Notarangelo A, D'Agruma L, Sacco M, et al. 2010 Calcium-sensing receptor (CASR) mutations in hypercalcemic states: studies from a single endocrine clinic over three years. Journal of Clinical Endocrinology and Metabolism 95 1819-1829. (https://doi. org/10.1210/jc.2008-2430)

Guarnieri V, Battista C, Muscarella LA, Bisceglia M, De Martino D, Baorda F, Maiello E, D'Agruma L, Chiodini I, Clemente C, et al. 2012 CDC73 mutations and parafibromin immunohistochemistry in parathyroid tumors: clinical correlations in a single-centre patient cohort. Cellular Oncology 35 411-422. (https://doi.org/10.1007/ s13402-012-0100-x)

Haglund F, Rosin G, Nilsson IL, Juhlin CC, Pernow Y, Norenstedt S, Dinets A, Larsson C, Hartman J \& Höög A 2015 Tumour nuclear oestrogen receptor beta 1 correlates inversely with parathyroid tumour weight. Endocrine Connections 4 76-85. (https://doi. org/10.1530/EC-14-0109)
Haven CJ, Howell VM, Eilers PH, Dunne R, Takahashi M, van Puijenbroek M, Furge K, Kievit J, Tan MH, Fleuren GJ, et al. 2004 Gene expression of parathyroid tumors: molecular subclassification and identification of the potential malignant phenotype. Cancer Research 64 7405-7411. (https://doi.org/10.1158/0008-5472.CAN04-2063)

Hosny Mohammed K, Siddiqui MT, Willis BC, Zaharieva Tsvetkova D, Mohamed A, Patel S, Sharma J, Weber C \& Cohen C 2017 Parafibromin, APC, and MIB-1 are useful markers for distinguishing parathyroid carcinomas from adenomas. Applied Immunohistochemistry and Molecular Morphology 25 731-735. (https:// doi.org/10.1097/PAI.0000000000000378)

Hosokawa Y, Pollak MR, Brown EM \& Arnold A 1995 Mutational analysis of the extracellular $\mathrm{Ca}(2+)$-sensing receptor gene in human parathyroid tumors. Journal of Clinical Endocrinology and Metabolism 80 3107-3110. (https://doi.org/10.1210/ jcem.80.11.7593409)

Howell VM, Haven CJ, Kahnoski K, Khoo SK, Petillo D, Chen J, Fleuren GJ, Robinson BG, Delbridge LW, Philips J, et al. 2003 HRPT2 mutations are associated with malignancy in sporadic parathyroid tumours. Journal of Medical Genetics 40 657-663. (https://doi. org/10.1136/jmg.40.9.657)

Howell VM, Gill A, Clarkson A, Nelson AE, Dunne R, Delbridge LW, Robinson BG, Teh BT, Gimm O \& Marsh DJ 2009 Accuracy of combined protein gene product 9.5 and parafibromin markers for immunohistochemical diagnosis of parathyroid carcinoma. Journal of Clinical Endocrinology and Metabolism 94 434-441. (https://doi. org/10.1210/jc.2008-1740)

Hu Y, Liao Q, Cao S, Gao X \& Zhao Y 2016 Diagnostic performance of parafibromin immunohistochemical staining for sporadic parathyroid carcinoma: a meta-analysis. Endocrine 54 612-619. (https://doi.org/10.1007/s12020-016-0997-3)

Hu Y, Cui M, Xia Y, Su Z, Zhang X, Liao Q, Jiang Y \& Zhao Y 2018 The clinical features of cystic parathyroid adenoma in Chinese population: a single-center experience. International Journal of Endocrinology 2018 3745239. (https://doi. org/10.1155/2018/3745239)

Ippolito G, Palazzo FF, Sebag F, De Micco C \& Henry JF 2007 Intraoperative diagnosis and treatment of parathyroid cancer and atypical parathyroid adenoma. British Journal of Surgery 94 566-570. (https://doi.org/10.1002/bjs.5570)

Juhlin C, Larsson C, Yakoleva T, Leibiger I, Leibiger B, Alimov A, Weber G, Höög A \& Villablanca A 2006 Loss of parafibromin expression in a subset of parathyroid adenomas. Endocrine-Related Cancer 13 509-523. (https://doi.org/10.1677/erc.1.01058)

Juhlin CC, Villablanca A, Sandelin K, Haglund F, Nordenström J, Forsberg L, Bränström R, Obara T, Arnold A, Larsson C, et al. 2007 Parafibromin immunoreactivity: its use as an additional diagnostic marker for parathyroid tumor classification. Endocrine-Related Cancer 14 501-512. (https://doi.org/10.1677/ERC-07-0021)

Juhlin CC, Nilsson IL, Johansson K, Haglund F, Villablanca A, Höög A \& Larsson C 2010 Parafibromin and APC as screening markers for malignant potential in atypical parathyroid adenomas. Endocrine Pathology 21 166-177. (https://doi.org/10.1007/s12022-0109121-z)

Juhlin CC, Haglund F, Obara T, Arnold A, Larsson C \& Höög A 2011 Absence of nucleolar parafibromin immunoreactivity in subsets of parathyroid malignant tumours. Virchows Archiv 459 47-53. (https:// doi.org/10.1007/s00428-010-1032-3)

Juhlin CC, Nilsson IL, Lagerstedt-Robinson K, Stenman A, Bränström R, Tham E \& Höög A 2019 Parafibromin immunostainings of parathyroid tumors in clinical routine: a near-decade experience from a tertiary center. Modern Pathology [epub]. (https://doi. org/10.1038/s41379-019-0252-6)

Karaarslan S, Yurum FN, Kumbaraci BS, Pala EE, Sivrikoz ON, Akyildiz M \& Bugdayci MH 2015 The role of parafibromin, galectin-3, HBME-1, 
and Ki-67 in the differential diagnosis of parathyroid tumors. Oman Medical Journal 30 421-427. (https://doi.org/10.5001/omj.2015.84)

Katz L, Abdel Khalek M, Crawford B \& Kandil E 2012 Robotic-assisted transaxillary parathyroidectomy of an atypical adenoma. Minimally Invasive Therapy and Allied Technologies 21 201-205. (https://doi.org/ 10.3109/13645706.2011.581291)

Kelly TG, Shattuck TM, Reyes-Mugica M, Stewart AF, Simonds WF, Udelsman R, Arnold A \& Carpenter TO 2006 Surveillance for early detection of aggressive parathyroid disease: carcinoma and atypical adenoma in familial isolated hyperparathyroidism associated with a germline HRPT2 mutation. Journal of Bone and Mineral Research 21 1666-1671. (https://doi.org/10.1359/jbmr.060702)

Kishikawa S, Shan L, Ogihara K, Utsunomiya H, Nakamura M, Nakamura Y, Naito A \& Kakudo K 1999 Overexpression and genetic abnormality of p53 in parathyroid adenomas. Pathology International 49 853-857. (https://doi.org/10.1046/j.1440-1827.1999.00961.x)

Korpi-Hyövälti E, Cranston T, Ryhänen E, Arola J, Aittomäki K, Sane T, Thakker RV. \& Schalin-Jäntti C 2014 CDC73 intragenic deletion in familial primary hyperparathyroidism associated with parathyroid carcinoma. Journal of Clinical Endocrinology and Metabolism 99 3044-3048. (https://doi.org/10.1210/jc.2014-1481)

Krebs LJ, Shattuck TM \& Arnold A 2005 HRPT2 mutational analysis of typical sporadic parathyroid adenomas. Journal of Clinical Endocrinology and Metabolism 90 5015-5017. (https://doi. org/10.1210/jc.2005-0717)

Kruijff S, Sidhu SB, Sywak MS, Gill AJ \& Delbridge LW 2014 Negative parafibromin staining predicts malignant behavior in atypical parathyroid adenomas. Annals of Surgical Oncology 21 426-433. (https://doi.org/10.1245/s10434-013-3288-8)

Kumari N, Chaudhary N, Pradhan R, Agarwal A \& Krishnani N 2016 Role of histological criteria and immunohistochemical markers in predicting risk of malignancy in parathyroid neoplasms. Endocrine Pathology 27 87-96. (https://doi.org/10.1007/s12022-016-9426-7)

Kwok GT, Zhao JT, Weiss J, Mugridge N, Brahmbhatt H, MacDiarmid JA, Robinson BG \& Sidhu SB 2017 Translational applications of microRNAs in cancer, and therapeutic implications. Non-Coding RNA Research 2 143-150. (https://doi.org/10.1016/j.ncrna.2017.12.002)

Lloyd RV, Carney JA, Ferreiro JA, Jin L, Thompson GB, van Heerden JA, Grant CS \& Wollan PC 1995 Immunohistochemical analysis of the cell cycle-associated antigens Ki-67 and retinoblastoma protein in parathyroid carcinomas and adenomas. Endocrine Pathology 6 279-287. (https://doi.org/10.1007/BF02738728)

Mamedova E, Mokrysheva N, Vasilyev E, Petrov V, Pigarova E, Kuznetsov S, Kuznetsov N, Rozhinskaya L, Melnichenko G, Dedov I, et al. 2017 Primary hyperparathyroidism in young patients in Russia: high frequency of hyperparathyroidism-jaw tumor syndrome. Endocrine Connections 6 557-565. (https://doi. org/10.1530/EC-17-0126)

Marx SJ \& Goltzman D 2019 Evolution of our understanding of the hyperparathyroid syndromes: a historical perspective. Journal of Bone and Mineral Research 34 22-37. (https://doi.org/10.1002/ jbmr.3650)

McCoy KL, Seethala RR, Armstrong MJ, Nikiforova MN, Stang MT, Carty SE \& Yip L 2015 The clinical importance of parathyroid atypia: is long-term surveillance necessary? Surgery 158 929-935; discussion 935. (https://doi.org/10.1016/j.surg.2015.06.022)

Menon SS, Guruvayoorappan C, Sakthivel KM \& Rasmi RR 2019 Ki-67 protein as a tumour proliferation marker. Clinica Chimica Acta 491 39-45. (https://doi.org/10.1016/j.cca.2019.01.011)

Mishra A \& Newman D 2014 An interesting case of life-threatening hypercalcemia secondary to atypical parathyroid adenoma versus parathyroid carcinoma. Case Reports in Medicine 2014473814. (https://doi.org/10.1155/2014/473814)

Mizusawa N, Uchino S, Iwata T, Tsuyuguchi M, Suzuki Y, Mizukoshi T, Yamashita Y, Sakurai A, Suzuki S, Beniko M, et al. 2006 Genetic analyses in patients with familial isolated hyperparathyroidism and hyperparathyroidism-jaw tumour syndrome. Clinical Endocrinology 65 9-16. (https://doi.org/10.1111/j.1365-2265.2006.02534.x)

Muscarella LA, Turchetti D, Fontana A, Baorda F, Palumbo O, la Torre A, de Martino D, Franco R, Losito NS, Repaci A, et al. 2018 Large deletion at the CDC73 gene locus and search for predictive markers of the presence of a CDC73 genetic lesion. Oncotarget 9 20721-20733. (https://doi.org/10.18632/oncotarget.25067)

Nair CG, Menon R, Jacob P \& Babu M 2013 Lithium-induced parathyroid dysfunction: a new case. Indian Journal of Endocrinology and Metabolism 17 930-932. (https://doi.org/10.4103/22308210.117223)

Nonaka D 2011 Study of parathyroid transcription factor Gcm2 expression in parathyroid lesions. American Journal of Surgical Pathology 35 145-151. (https://doi.org/10.1097/ PAS.0b013e31820371e4)

O'Neal P, Mowschenson P, Connolly J \& Hasselgren PO 2011 Large parathyroid tumors have an increased risk of atypia and carcinoma. American Journal of Surgery 202 146-150. (https://doi.org/10.1016/j. amjsurg.2010.06.003)

Onoda N, Ogisawa K, Ishikawa T, Takenaka C, Tahara H, Inaba M, Takashima T \& Hirakawa K 2004 Telomerase activation and expression of its catalytic subunits in benign and malignant tumors of the parathyroid. Surgery Today 34 389-393. (https://doi. org/10.1007/s00595-003-2729-6)

Osawa N, Onoda N, Kawajiri H, Tezuka K, Takashima T, Ishikawa T, Miyauki A, Hirokawa M, Wakasa K \& Hirakawa K 2009 Diagnosis of parathyroid carcinoma using immunohistochemical staining against hTERT. International Journal of Molecular Medicine 24 733-741. (https://doi.org/10.3892/ijmm_00000286)

Ozolins A, Narbuts Z, Vanags A, Simtniece Z, Visnevska Z, Akca A, Wirowski D, Gardovskis J, Strumfa I \& Goretzki PE 2016 Evaluation of malignant parathyroid tumours in two European cohorts of patients with sporadic primary hyperparathyroidism. Langenbeck's Archives of Surgery 401 943-951. (https://doi.org/10.1007/s00423015-1361-4)

Pal R, Bhadada SK, Dutta P, Behera A, Talukder S, Saikia UN, Mitra S, Kaur G \& Bhansali A 2018 Ectopic atypical parathyroid neoplasm in a patient with multiple endocrine neoplasia type I. AACE Clinical Case Reports 4 e383-e387. (https://doi.org/10.4158/accr-2018-0002)

Pardi E, Marcocci C, Borsari S, Saponaro F, Torregrossa L, Tancredi M, Raspini B, Basolo F \& Cetani F 2013 Aryl hydrocarbon receptor interacting protein (AIP) mutations occur rarely in sporadic parathyroid adenomas. Journal of Clinical Endocrinology and Metabolism 98 2800-2810. (https://doi.org/10.1210/jc.2012-4029)

Pazienza V, La Torre A, Baorda F, Alfarano M, Chetta M, Muscarella LA, Battista C, Copetti M, Kotzot D, Kapelari K, et al. 2013 Identification and functional characterization of three NoLS (nucleolar localisation signals) mutations of the CDC73 gene. PLOS ONE 8 e82292. (https:// doi.org/10.1371/journal.pone.0082292)

Phitayakorn R \& McHenry CR 2006 Incidence and location of ectopic abnormal parathyroid glands. American Journal of Surgery 191 418-423. (https://doi.org/10.1016/j.amjsurg.2005.10.049)

Quinn CE, Healy J, Lebastchi AH, Brown TC, Stein JE, Prasad ML, Callender GG, Carling T \& Udelsman R 2015 Modern experience with aggressive parathyroid tumors in a high-volume new England referral center. Journal of the American College of Surgeons 220 1054-1062. (https://doi.org/10.1016/j.jamcollsurg.2014.10.007)

Ramaswamy AS, Vijitha T, Kumarguru BN \& Mahalingashetti PB 2017 Atypical parathyroid adenoma. Indian Journal of Pathology and Microbiology 60 99-101. (https://doi.org/10.4103/03774929.200055)

Ricci G, Assenza M, Barreca M, Liotta G, Paganelli L, Serao A, Tufodandria G \& Marini P 2012 Parathyroid carcinoma: the importance of high clinical suspicion for a correct management. International Journal of Surgical Oncology 2012 649148. (https://doi. org/10.1155/2012/649148) https://erc.bioscientifica.com

https://doi.org/10.1530/ERC-19-0135 (c) 2019 Society for Endocrinology Published by Bioscientifica Ltd. Printed in Great Britain 
Romano R, Soong CP, Rose M, Costa-Guda J, Bellizzi J \& Arnold A 2017 EZH2 copy number and mutational analyses in sporadic parathyroid adenomas. Endocrine 55 985-988. (https://doi.org/10.1007/s12020016-1142-z)

Rosai J, DeLellis R, Carcangiu M, Frable W \& Tallin G 2014 Parathyroid adenoma and variants. In Tumors of the Thyroid and Parathyroid Glands. Armed Forces Institute of Pathology; Atlas of Tumor Patology 4th Series. pp. 513-542. Silver Spring, MD, USA: American Registry of Pathology.

Roy M, Mazeh H, Chen H \& Sippel RS 2013 Incidence and localization of ectopic parathyroid adenomas in previously unexplored patients. World Journal of Surgery 37 102-106. (https://doi.org/10.1007/s00268012-1773-z)

Ryhänen EM, Leijon H, Metso S, Eloranta E, Korsoff P, Ahtiainen P, Kekäläinen P, Tamminen M, Ristamäki R, Knutar O, et al. 2017 A nationwide study on parathyroid carcinoma. Acta Oncologica 56 991-1003. (https://doi.org/10.1080/0284186X.2017.1306103)

Sandelin K, Tullgren O \& Farnebo LO 1994 Clinical course of metastatic parathyroid cancer. World Journal of Surgery 18 594-598; discussion 599. (https://doi.org/10.1007/BF00353773)

Sanpaolo E, Miroballo M, Corbetta S, Verdelli C, Baorda F, Balsamo T, Graziano P, Fabrizio FP, Cinque L, Scillitani A, et al. 2016 EZH2 and ZFX oncogenes in malignant behaviour of parathyroid neoplasms. Endocrine 54 55-59. (https://doi.org/10.1007/s12020016-0892-y)

Saponaro F, Cetani F, Repaci A, Pagotto U, Cipriani C, Pepe J, Minisola S, Cipri C, Vescini F, Scillitani A, et al. 2018 Clinical presentation and management of patients with primary hyperparathyroidism in Italy. Journal of Endocrinological Investigation 41 1339-1348. (https://doi. org/10.1007/s40618-018-0879-z)

Sarquis MS, Silveira LG, Pimenta FJ, Dias EP, Teh BT, Friedman E, Gomez RS, Tavares GC, Eng C \& De Marco L 2008 Familial hyperparathyroidism: surgical outcome after 30 years of follow-up in three families with germline HRPT2 mutations. Surgery 143 630-640. (https://doi.org/10.1016/j.surg.2007.12.012)

Schantz A \& Castleman B 1973 Parathyroid carcinoma. A study of 70 cases. Cancer 31 600-605. (https://doi.org/10.1002/10970142(197303)31:3<600::AID-CNCR2820310316>3.0.CO;2-0)

Schneider R, Bartsch-Herzog S, Ramaswamy A, Bartsch DK \& Karakas E 2015 Immunohistochemical expression of E-cadherin in atypical parathyroid adenoma. World Journal of Surgery 39 2477-2483. (https://doi.org/10.1007/s00268-015-3149-7)

Seethala R, Ogilvie J \& Virji M 2009 Pathology of the parathyroid glands. In Surgical Pathology of the Head and Neck, pp 1429-1472. Ed E Barnes. New York, NY, USA: Taylor and Francis.

Silva-Figueroa A, Villalobos P, Williams MD, Bassett RL, Clarke CN, Lee JE, Busaidy NL \& Perrier ND 2018 Characterizing parathyroid carcinomas and atypical neoplasms based on the expression of programmed death-ligand 1 expression and the presence of tumorinfiltrating lymphocytes and macrophages. Surgery $164960-964$. (https://doi.org/10.1016/j.surg.2018.06.013)

Starker LF, Svedlund J, Udelsman R, Dralle H, Åkerström G, Westin G, Lifton RP, Björklund P \& Carling T 2011 The DNA methylome of benign and malignant parathyroid tumors. Genes, Chromosomes and Cancer 50 735-745. (https://doi.org/10.1002/gcc.20895)

Stojadinovic A, Hoos A, Nissan A, Dudas ME, Cordon-Cardo C, Shaha AR, Brennan MF, Singh B \& Ghossein RA 2003 Parathyroid neoplasms: clinical, histopathological, and tissue microarray-based molecular analysis. Human Pathology 34 54-64. (https://doi. org/10.1053/hupa.2003.55)

Sulaiman L, Nilsson IL, Juhlin CC, Haglund F, Höög A, Larsson C \& Hashemi J 2012a Genetic characterization of large parathyroid adenomas. Endocrine-Related Cancer 19 389-407. (https://doi. org/10.1530/ERC-11-0140)

Sulaiman L, Haglund F, Hashemi J, Obara T, Nordenström J, Larsson C \& Juhlin CC $2012 b$ Genome-wide and locus specific alterations in
CDC73/HRPT2-mutated parathyroid tumors. PLoS ONE 7 e46325. (https://doi.org/10.1371/journal.pone.0046325)

Sulaiman L, Juhlin CC, Nilsson IL, Fotouhi O, Larsson C \& Hashemi J 2013 Global and gene-specific promoter methylation analysis in primary hyperparathyroidism. Epigenetics 8 646-655. (https://doi. org/10.4161/epi.24823)

Sungu N, Dogan HT, Kiliçarslan A, Kiliç M, Polat S, Tokaç M, Akbaba S, Parlak Ö, Balci S, Ögüt B, et al. 2018 Role of calcium-sensing receptor, galectin-3, cyclin D1, and Ki-67 immunohistochemistry to favor in the diagnosis of parathyroid carcinoma. Indian Journal of Pathology and Microbiology 61 22-26. (https://doi.org/10.4103/IJPM. IJPM_85_17)

Svedlund J, Aurén M, Sundström M, Dralle H, Åkerström G, Björklund P \& Westin G 2010 Aberrant WNT/b-catenin signaling in parathyroid carcinoma. Molecular Cancer 9 294. (https://doi.org/10.1186/14764598-9-294)

Tan M-H, Morrison C, Wang P, Yang X, Haven CJ, Zhang C, Zhao P, Tretiakova MS, Korpi-Hyovalti E \& Burgess JR 2004 of parafibromin immunoreactivity is a distinguishing feature of parathyroid carcinoma. Clinical Cancer Research 10 6629-6637. (https://doi. org/10.1158/1078-0432.CCR-04-0493)

Teh BT, Farnebo F, Twigg S, Höög A, Kytölä S, Korpi-Hyövälti E, Wong FK, Nordenström J, Grimelius L, Sandelin K, et al. 1998 Familial isolated hyperparathyroidism maps to the Hyperparathyroidism-jaw tumor locus in 1q21-q32 in a subset of families. Journal of Clinical Endocrinlology and Metabolism $\mathbf{8 3}$ 2114-21120. (https://doi.org/10.1210/jcem.83.6.4896)

Truran PP, Johnson SJ, Bliss RD, Lennard TWJ \& Aspinall SR 2014 Parafibromin, galectin-3, PGP9.5, Ki67, and cyclin D1: using an immunohistochemical panel to aid in the diagnosis of parathyroid cancer. World Journal of Surgery 38 2845-2854. (https://doi. org/10.1007/s00268-014-2700-2)

Van Der Tuin K, Tops CMJ, Adank MA, Cobben JM, Hamdy NAT, Jongmans MC, Menko FH, Van Nesselrooij BPM, Netea-Maier RT, Oosterwijk JC, et al. 2017 CDC73-related disorders: clinical manifestations and case detection in primary hyperparathyroidism. Journal of Clinical Endocrinology and Metabolism 102 4534-4540. (doi:10.1210/jc.2017-01249)

Vargas M, Vargas H, Kleiner D \& Merino M 1997 The role of prognostic markers (MiB-1, RB, and bcl-2) in the diagnosis of parathyroid tumors. Modern Pathology 10 12-17.

Verdelli C \& Corbetta S 2017 Epigenetic alterations in parathyroid cancers. International Journal of Molecular Sciences 18 1-13. (https:// doi.org/10.3390/ijms18020310)

Verdelli C, Avagliano L, Creo P, Guarnieri V, Scillitani A, Vicentini L, Steffano GB, Beretta E, Soldati L, Costa E, et al. 2015 Tumourassociated fibroblasts contribute to neoangiogenesis in human parathyroid neoplasia. Endocrine-Related Cancer 22 87-98. (https:// doi.org/10.1530/ERC-14-0161)

Verdelli C, Forno I, Morotti A, Creo P, Guarnieri V, Scillitani A, Cetani F, Vicentini L, Balza G, Beretta E, et al. 2018 The aberrantly expressed miR-372 partly impairs sensitivity to apoptosis in parathyroid tumor cells. Endocrine-Related Cancer 25 761-771. (https://doi.org/10.1530/ ERC-17-0204)

Vogelstein B, Papadopoulos N, Velculescu VE, Zhou S, Diaz Jr LA \& Kinzler KW 2013 Cancer genome landscapes. Science 339 1546-1558. (https://doi.org/10.1126/science.1235122)

Walls GV, Stevenson M, Lines KE, Newey PJ, Reed AAC, Bowl MR, Jeyabalan J, Harding B, Bradley KJ, Manek S, et al. 2017 Mice deleted for cell division cycle 73 gene develop parathyroid and uterine tumours: model for the hyperparathyroidism-jaw tumour syndrome. Oncogene 36 4025-4036. (https://doi.org/10.1038/ onc.2017.43)

Witteveen JE, Hamdy NA, Dekkers OM, Kievit J, van Wezel T, Teh BT, Romijn JA \& Morreau H 2011 Downregulation of CASR expression and global loss of parafibromin staining are strong (c) 2019 Society for Endocrinology Published by Bioscientifica Ltd. Printed in Great Britain 
negative determinants of prognosis in parathyroid carcinoma. Modern Pathology 24 688-697. (https://doi.org/10.1038/ modpathol.2010.236)

Yener S, Saklamaz A, Demir T, Kebapcilar L, Bayraktar F, Canda S \& Yesil S 2014 Primary hyperparathyroidism due to atypical parathyroid adenoma presenting with peroneus brevis tendon rupture. Journal of Endocrinological Investigation 30 442-444. (https:// doi.org/10.1007/bf03346325)

Yip L, Seethala RR, Nikiforova MN, Nikiforov YE, Ogilvie JB, Carty SE \& Yim JH 2008 Loss of heterozygosity of selected tumor suppressor genes in parathyroid carcinoma. Surgery 144 949-955; discussion 954. (https://doi.org/10.1016/j.surg.2008.08.030)

Received in final form 7 May 2019

Accepted 14 May 2019

Accepted Preprint published online 14 May 2019
C) 2019 Society for Endocrinology Published by Bioscientifica Ltd. 